Copyright

by

Jinsong Liu

2015 
The Thesis Committee for Jinsong Liu

certifies that this is the approved version of the following thesis:

\section{On the Development of a Semi-Submersible Offshore Floating Platform and Mooring System for a 13.2 MW Wind Turbine}

APPROVED BY
SUPERVISING COMMITTEE:

Lance Manuel, Supervisor

Spyros A. Kinnas 


\title{
On the Development of a Semi-Submersible Offshore Floating Platform and Mooring System for a 13.2 MW Wind Turbine
}

\author{
by \\ Jinsong Liu, B.S.
}

\author{
THESIS \\ Presented to the Faculty of the Graduate School of \\ The University of Texas at Austin \\ in Partial Fulfillment \\ of the Requirements \\ for the Degree of \\ Master of Science in Engineering
}

THE UNIVERSITY OF TEXAS AT AUSTIN

December 2015 
Dedicated to my parents and sisters 


\section{Acknowledgments}

First and foremost, I would like to express deepest gratitude to my supervisor, Dr. Lance Manuel, who has supported me throughout my thesis with his patience and knowledge. His encouragement and guidance to complete the project is greatly appreciated; without him this thesis would not have been completed or written. I would also like to thank Dr. Spyros A. Kinnas for serving on my committee and for his generous help with my study and life.

I would like to thank my colleague, Mr. Edwin Thomas, who has being a great partner solving many problems and has inspired me to think broadly.

Special gratitude to Dr. Todd (Daniel) Griffith and Ms. Kelley Ruehl of Sandia National laboratories for providing the blade models, and for assistance throughout the project. The financial support from Sandia National Laboratories by way of Contract No. 1307455 for this research is gratefully acknowledged.

Finally, I would like to thank my beloved parents and sisters for their unconditional support. Without them, I would never finish this work. 


\begin{abstract}
On the Development of a Semi-Submersible Offshore Floating Platform and Mooring System for a 13.2 MW Wind Turbine
\end{abstract}

\author{
Jinsong Liu, M.S.E. \\ The University of Texas at Austin, 2015
}

Supervisor: Lance Manuel

Over the past decades, wind energy has emerged as an alternative to conventional power generation that is economical, environmentally friendly, and importantly renewable. Specifically, offshore wind energy is being considered by a number of countries to harness the stronger and more consistent wind resource compared to that over land. To meet the projected " $20 \%$ energy from wind by 2030" scenario that was announced in 2006, 54 GW of added wind energy capacity needs to come from offshore according to a National Renewable Energy Laboratory (NREL) study.

In this study, we discuss the development of a semi-submersible floating offshore platform with a catenary mooring system to support a very large 
13.2 MW wind turbine with $100 \mathrm{~m}$ blades. An iterative design process is applied to baseline models with Froude scaling in order to achieve preliminary static stability. Structural dynamic analyses are performed to investigate the performance of the new model using a finite element method approach for the tower and a boundary integral equation (panel) method for the platform. The steady-state response of the system under uniform wind and regular waves is first studied to evaluate the performance of the integrated system. Response amplitude operators (RAOs) are computed in the time domain using whitenoise wave excitation; this serves to highlight nonlinear as well as dynamic characteristics of the system. Finally, the stochastic dynamic response of the system is studied to assess the global performance for sea states defined by wind fields with turbulence and long-crested irregular waves. 


\section{Table of Contents}

Acknowledgments $\quad$ v

Abstract vi vi vi vis

List of Tables $\quad$ x

List of Figures $\quad$ xi

Chapter 1. Introduction 1

1.1 Background ..................... 1

1.2 Research Objectives and Methodology . . . . . . . . . . . 4

1.3 Limitations of this Study . . . . . . . . . . . . . . . 5

1.4 Organization of Thesis . . . . . . . . . . . . 6

Chapter 2. Model Development 8

2.1 Design Methodology . . . . . . . . . . . . . . . 9

2.2 SNL 13.2 MW Baseline Turbine Properties . . . . . . . . . . . 11

2.3 Baseline Semi-submersible Platform and Mooring System . . . 14

2.4 Iterations in Model Scaling . . . . . . . . . . . . . . . 17

Chapter 3. Properties of Final Wind Turbine and Semi-submersible Platform $\quad 27$

3.1 Tower Dynamic Properties . . . . . . . . . . . . . . . . 27

3.2 Platform Hydrodynamic Properties . . . . . . . . . . . . . . . 30

3.2.1 Keulegan-Carpenter number: Flow-Structure Interaction 31

3.2.2 MultiSurf: Platform Model Geometry . . . . . . . . . . 34

3.2.3 WAMIT: Potential Flow Theory . . . . . . . . . . 35

3.2.4 HydroDyn: Morsion's Equation . . . . . . . . . . . 36

viii 
Chapter 4. Response Analysis of the Integrated System 40

4.1 Steady-state response analysis . . . . . . . . . . . . 41

4.1 .1 Free-decay simulation . . . . . . . . . . . . . . . 41

4.1.2 Steady-state response of integrated system under uniform wind and regular waves . . . . . . . . . . . . . . 42

4.1 .3 Response Amplitude Operators . . . . . . . . . . . . . 43

4.2 Dynamic Response Analysis under Turbulent Winds and Irregular Waves . . . . . . . . . . . . . . . . . . . . . . 49

Chapter 5. Conclusions 54

5.1 Summary and Conclusions . . . . . . . . . . . . 54

5.2 Suggestions for Future Research . . . . . . . . . . . . 56

$\begin{array}{ll}\text { Bibliography } & 58\end{array}$

$\begin{array}{ll}\text { Vita } & 64\end{array}$ 


\section{List of Tables}

2.1 Key differences between the different SNL 100 meter blade designs. 12

2.2 Properties of the SNL $13.2 \mathrm{MW}$ wind turbine. . . . . . . . . . 14

2.3 The OC4-DeepCwind floating system geometry and structural properties. . . . . . . . . . . . . . 16

2.4 Mooring system properties. . . . . . . . . . . . . . . . 18

2.5 Froude scaling used in the model development. . . . . . . . . . 24

2.6 Alternative models and evaluations against pitch motion criteria. 24

2.7 Alternative models and evaluations against heave motion criteria. 24

2.8 Distributed Geometric and Structural Properties for the $115.6 \mathrm{~m}$ Tower for the SNL 13.2 MW Wind Turbine. . . . . . . . . . 25

3.1 Sea states defined by wave spectral peak period, $T$, and significant wave height, $H_{s}$, selected for the dynamic analyses. . . . 34

3.2 Floating platform hydrodynamic properties. . . . . . . . . . . 39

4.1 Selected sea states for short-term response analysis. . . . . . . 43

4.2 Maximum values of the steady-state response of the integrated system. . . . . . . . . . . . . . . . . 45

4.3 Statistics of the SNL 13.2 MW turbine's platform pitch motion. 53 


\section{List of Figures}

1.1 Floating offshore wind turbine concepts. . . . . . . . . . . 3

2.1 Iterations in the model development. . . . . . . . . . . . . . . 10

2.2 Variation in mass density, flapwise stiffness, and edgewise stiffness along the (normalized) length for three SNL 100-meter blade designs and for the NREL 5-MW wind turbine blade. . .

2.3 The OC4-DeepCwind semi-submersible platform: plan and elevation. . . . . . . . . . . . . . . 15

2.4 Mooring line arrangement. . . . . . . . . . . . . . . . . . . 19

2.5 Integrated system showing Sandia 13.2 MW wind turbine, tower, semi-submersible floating platform, and mooring lines. . . . . 26

3.1 First two tower mode shapes. . . . . . . . . . . . . . . . . . . 29

3.2 Campbell diagram for the SNL 13.2 MW wind turbine with SNL100-02 blades and a $118.5 \mathrm{~m}$ tower. . . . . . . . . . . 30

$3.3 \mathrm{KC}$ numbers for the SNL semi-submersible platform. . . . . . 33

3.4 MultiSurf model of the SNL semi-submersible platform. . . . . 35

3.5 SNL semi-submersible platform added mass and damping coefficients for a zero wave heading. . . . . . . . . . . . .

3.6 SNL semi-submersible platform added mass and damping coefficients for a zero wave heading. . . . . . . . . . . .

3.7 SNL semi-submersible platform excitation force coefficients for a zero wave heading. . . . . . . . . . . . . . .

4.1 Free-decay simulation of the integrated system model following an initial heave displacement of 2 meters. . . . . . . . . .

4.2 Time series of the integrated system for a unit-amplitude wave at surge natural frequency of $0.0057 \mathrm{~Hz}$ (for rated wind velocity, $\left.V_{\text {rated }}=11.3 \mathrm{~m} / \mathrm{s}\right) \ldots \ldots \ldots \ldots$

4.3 SNL 13.2 MW turbine's semi-submersible platform RAOs under zero wind speed . . . . . . . . . . . . . . 47

4.4 OC4 DeepCwind Semi-submersible RAOs under zero wind speed 48 
4.5 One-hour time series of the SNL 13.2 MW turbine-platform integrated system $\left(V_{h u b}=11.3 \mathrm{~m} / \mathrm{s}, H_{s}=7.77 \mathrm{~m}, T_{p}=14.43 \mathrm{~s}\right) 51$

4.6 One-hour time series of the SNL 13.2 MW turbine-platform integrated system $\left(V_{h u b}=25.0 \mathrm{~m} / \mathrm{s}, H_{s}=11.52 \mathrm{~m}, T_{p}=14.31 \mathrm{~s}\right) 52$ 


\section{Chapter 1}

\section{Introduction}

\subsection{Background}

Over the last few decades, wind has emerged as an attractive alternative to conventional power generation and established itself as a major source of environmentally friendly and inexhaustible renewable energy. Globally, 51,473 MW of new wind power generation capacity was added in 2014, according to global wind market statistics by the Global Wind Energy Council (GWEC) [11], reflecting an increase of $44 \%$ after a brief slowdown in 2013. Ac-

cording to an American Wind Energy Association (AWEA) market report [1], by the end of the first quarter of 2015, the U.S. had an installed wind energy capacity of $66,008 \mathrm{MW}$ and over 48,000 operating turbines, compared with an 11,575 MW capacity in 2006 when the U.S. Department of Energy's "20\% energy from wind by 2030" projection scenario was announced. A National Renewable Energy Laboratory (NREL) cost study found that, to achieve the $20 \%$ target, 54 GW of added power generation capacity would need to come from offshore wind [20].

Several offshore wind turbine concepts have been proposed and studied both in the U.S. and in Europe that have explored the feasibility of utilizing 
offshore wind energy. In shallow to intermediate water depths up to $60 \mathrm{~m}$, conventional bottom-supported monopiles, tripods, and jacket structures can be deployed. In deeper waters, however, such as is the case for many U.S. offshore wind sites, floating platforms are more feasible and economical as support structures. To date, three principal floating platform configurations, as shown in Fig. 1.1, classified in terms of how these support structures achieve stability, have been considered. They are:

- shallow-draft platforms, such as barges with catenary mooring lines, that achieve stability via the extent of their water-plane area;

- deep-draft platforms, such as spars with moored catenary or taut lines, that achieve stability and pitch restoring moment via ballast;

- buoyancy-driven platforms, such as tension-leg platforms (TLPs), that achieve stability via a series mooring lines in tension.

Fully integrated offshore wind turbine system models have been developed based on the floating platform configurations mentioned above. Bulder et al. [4] investigated a tri-floater design for a 5-MW turbine. Wayman [35] and Jonkman [35] analyzed various TLP and barge designs with the NREL 5-MW wind turbine model. Tracy [33] conducted a parametric study to find the optimal TLP as well as slack and taut moored-line spar-bouy designs that had good overall performance in combination with low cost. A TLP model for a 5-MW turbine was the focus of a study by Denis [23]; its performance was 


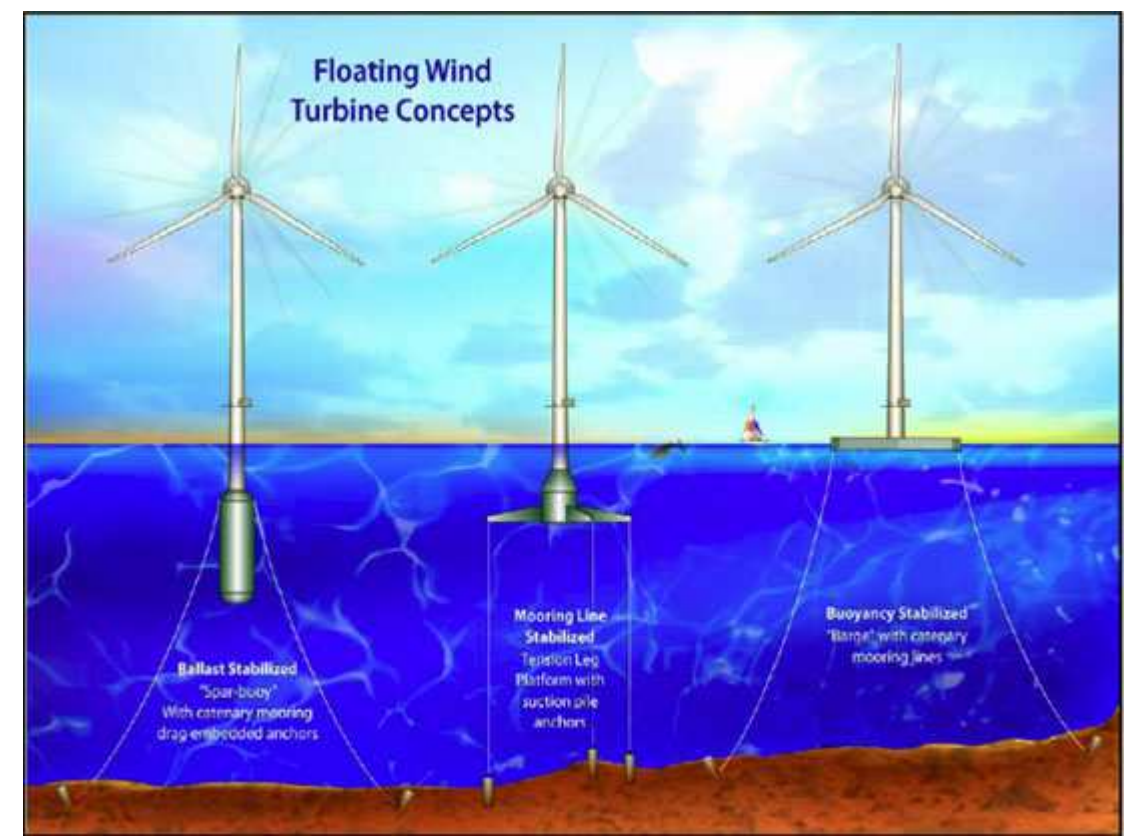

Figure 1.1: Floating offshore wind turbine concepts.

compared to that of other floating platform concepts in loads computations. It is worth noting that, as in the studies cited, much previous work has focused on the use of turbines with a 5-MW rating, and most often the selected model for such studies has been the NREL 5-MW offshore baseline wind turbine [15]. To take advantage of the economies of scale, the stronger and more consistent wind resource farther offshore, and the reduced transportation and construction constraints associated with the use of large turbines on land, the feasibility of using very large-scale wind turbines is being increasingly studied-such as with a 10-MW turbine studied in the European Union UpWind project. The present study, along similar lines, explores the use of a floating platform to a support a very large 13.2 MW wind turbine with $100 \mathrm{~m}$ blades. 


\section{$1.2 \quad$ Research Objectives and Methodology}

The objective of this study is to develop a semi-submersible floating platform model that will support an innovative 13.2 MW horizontal-axis wind turbine with 100-meter long blades that has been developed at Sandia National Laboratories (SNL) [10]. The OC4 semi-submersible floating offshore wind turbine [28] is selected as the base model to which Froude scaling is applied to develop the semi-submersible platform model for the SNL 13.2 MW turbine. An iterative design procedure is presented that seeks to describes the entire model development that considers cost as well as performance.

Fundamentally, at higher elevations above ground for land sites and above the mean sea level (MSL) for offshore sites, winds are stronger and less turbulent. From this point of view, then, a turbine's tower should be as high as practical to maximize energy capture. However, this would increase the cost of the integrated system.; thus, the choice of tower height is decided based on a economic trade-off between the increased energy capture versus the increased material costs. Additionally, for floating turbine systems, a heavier tower would generally require a larger supporting offshore platform for stability.

In this study, a minimum hub height above MSL of $133.5 \mathrm{~m}$ (representing a rotor radius $102.5 \mathrm{~m}$ and an air gap of $31 \mathrm{~m}$ ) above MSL is the starting point for the model development. With this selected starting point for the minimum tower height, then, a shorter tower is desired for the purpose of weight reduction, to limit the supporting platform size, and to reduce the tower bending moment requirements particularly in platform pitching mode. 
A reasonable air gap, representing clearance between wave crests and the lowest sweeping point of the rotor, is needed for vessel navigation purposes. This is the basis for the minimum clearance of $31 \mathrm{~m}$ between the blade tip at its lowest point and the mean sea level. It is desired next to size the floating platform so as to be as small as possible, yet still be able to support the topside structure (tower and turbine). Additionally, the platform must have adequate stability in its unmoored state and the integrated model must have natural frequencies that are out of the frequency range of dominant wave energy. Finally, mooring lines are assumed to be necessary for the integrated model to provide a station-keeping function.

\subsection{Limitations of this Study}

The ultimate goal of this study is to develop an economical design for an integrated system for a semi-submersible floating offshore platform that supports the selected large wind turbine. Even though we describe the development of a platform model that has been greatly reduced from an earlier model that used a upscaling by factor of 1.8 from the OC4 semi-submersible platform [30] to a factor of 1.5 and we employ a tower that was similarly reduced to meet design objectives, the developed model is not fully optimized and further refinements to the integrated turbine system are still possible. We will show that the platform geometry selected could possibly be revised

so as to provide greater pitch restoring capability. Upon studying response amplitude operators (RAO) for the designed platform model, we will note 
that natural frequencies for this platform are somewhat smaller than those for the OC4 platform. The influence of second-order slow-drift forces on a semi-submersible floating offshore wind turbine can be significant as has been demonstrated [2]; such effects can be more important for the system developed in this study. Finally, only a selected set of design load cases (DLCs) are considered in simulations to evaluate the turbine-platform system; extensive time-domain simulations considering other DLCs and external conditions,

per IEC 61400-3 [6], are recommended for a more complete validation of the integrated model performance.

\subsection{Organization of Thesis}

This thesis consists of four chapters in total.

In Chapter 1, a general introduction and the objectives and limitations of this study are presented. Chapter 2 outlines various considerations taken in the iterative design process that lead to development of the semi-submersible platform model for the 13.2 MW SNL wind turbine. An overview of baseline tower and platform models is presented. This includes details related to alternative SNL 100 m blade configurations, the OC4 semi-submersible platform's geometric and structural properties, and the mooring system. Heave and pitch motion constraints, considered in order to achieve preliminary scaling factors for both platform and mooring system, are described here.

In Chapter 3, properties of final wind turbine model are presented. The tower dynamic characteristics are discussed along with consideration for modes 
of vibration and resonance avoidance based on the applicable Campbell diagram. Potential flow theory is applied using WAMIT [18] to obtain platform hydrodynamic coefficients including added mass, damping, and excitation coefficients after consideration of the Keulegan-Carpenter (KC) number for each column in selected sea states.

In Chapter 4, the static and dynamic performance of the integrated turbine-platform system are evaluated using the aero-hydro-servo-elastic simulation tool, FAST [14], developed at the National Renewable Energy Laboratory (NREL). Free-decay simulation results are first presented to assess steady-state offsets and overall response to a uniform wind field and regular waves. Next, response amplitude operators (RAOs) are computed in the time domain based on white noise wave excitation using FAST in order to assess the overall dynamic performance of the system. Finally, the response of the integrated system under turbulent wind fields and for long-crested irregular waves is studied in order to assess various degrees of freedom (DOFs) of the system and overall performance.

Conclusions arising from this study and suggestions for future work are presented in Chapter 5. 


\section{Chapter 2}

\section{Model Development}

In order to be able to perform a stability and loads analysis using the simulation software, FAST, an integrated system consisting of a turbine, platform, and mooring system must be developed. Associated wind conditions and sea state definitions must be specified for evaluating the system performance. Because there are several inter-related characteristics of this integrated system, an iterative design procedure must be carried out to achieve the model development objectives.

The steps in the overall model development for the integrated system are first presented. Each step necessary to define and develop a FAST model of the system is presented; these steps undertaken are similar to those used to develop a TLP model by Matha [23]. At the initial stage of an innovative design such as this one involving a very large rotor, it is common to take advantage of completed studies of a similar nature. In this study, the OC4DeepCwind semi-submersible floating platform and offshore wind turbine [28] are chosen as the baseline model to which changes are made. Froude scaling is applied to this baseline configuration of the OC4-DeepCwind model to develop the SNL 13.2 MW turbine's semi-submersible platform model. Since the 
OC4-DeepCwind turbine and platform have been the subject of several major studies, the use of this OC4-DeepCwind model has the benefit that it helps to highlight the effects introduced by the use of a very large rotor.

\section{$2.1 \quad$ Design Methodology}

The iterative process for development of the new model begins by considering an earlier model [30] involving the SNL 13.2 MW wind turbine [10] supported on a scaled-up model of the OC4-DeepCwind semi-submersible platform. That model was analyzed in simulations under steady (non-turbulent) as well as turbulent wind fields and for both regular and irregular waves. A drawback of that earlier model [30] is that the large platform utilized therein was likely overdesigned to accommodate a taller tower and costs are estimated to likely be 5-6 times that of the OC4-DeepCwind platform. As will be shown later, this deficiency in the system can be corrected by appropriate modifications of the tower, the platform, and the mooring system. The objective of this study is to develop an integrated system model consisting of a tower, semisubmersible platform, and mooring system that can support the SNL 13.2 MW wind turbine, while meeting static and dynamic performance requirements and limiting overall system costs. In the model development iterations, the goal with each candidate model is to ensure that the system is statically stable and has an adequate air gap of 31 meters; subsequently, system dynamic performance is verified under different sea states with steady as well as turbulent winds and long-crested regular as well as irregular waves. Various performance 
requirements for the platform model development will be discusses; for example, one key performance parameter, related to platform pitch motion, defined for functionality, safe performance, and efficiency of the turbine, is to limit the pitch motions to 10 degrees in each intermediate model in the iterations.

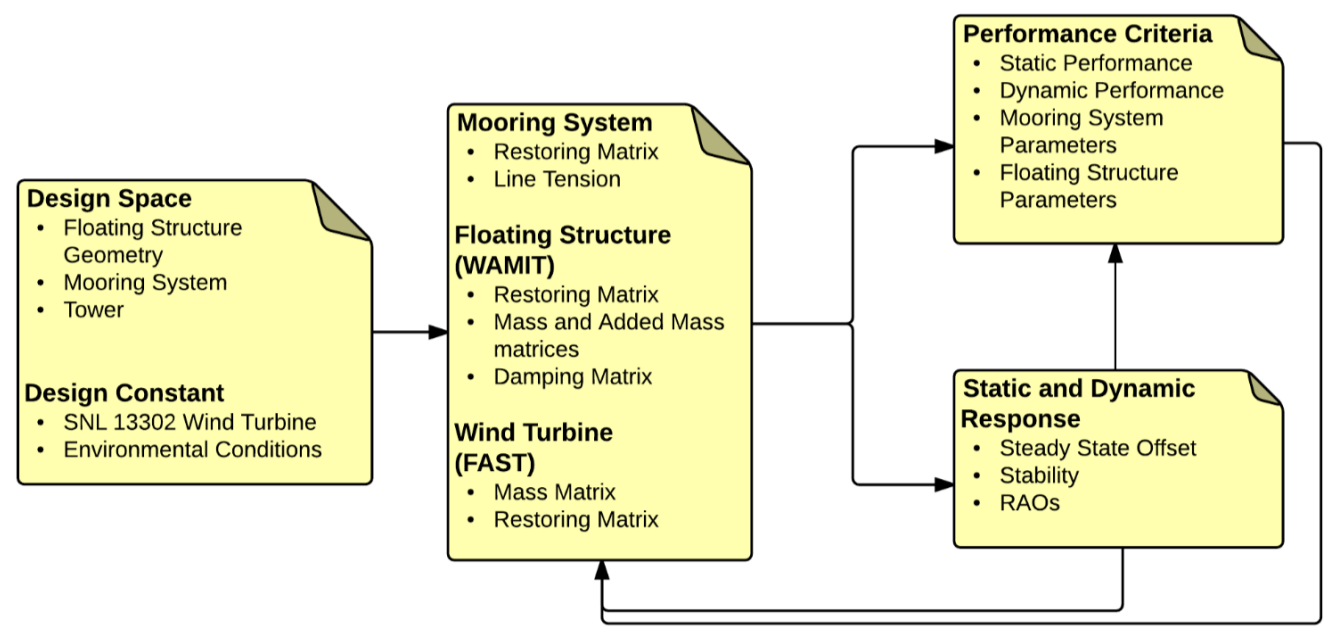

Figure 2.1: Iterations in the model development.

The iterative model development process is schematically presented in the flowchart shown in Fig. 2.1. From a series of SNL 100-meter blade models, which are discussed later, the SNL 133-02 blades are selected. This blade selection and the environmental conditions used in this study are considered "Design Constant" in the model development. The iterative procedure begins by considering available baseline models including the OC4-DeepCwind semisubmersible platform and mooring system and proceeds, per the flowchart 
presented in Fig. 2.1, through various system changes involving static as well as dynamic response computations and checks against specified performance criteria. After preliminary validation in frequency domain against global performance criteria, the system's static and dynamic performance in normal and extreme sea states is studied in time-domain simulations. In any step of the model development, failure to meet desired performance criteria requires model changes iteratively.

\subsection{SNL 13.2 MW Baseline Turbine Properties}

A series of studies have been undertaken toward the development of a 100-meter blade design for a 13.2 MW horizontal-axis wind turbine by Sandia National Laboratories (SNL). Four different designs have been proposed with different materials as well as innovations in the blade geometry. All these blade models are publicly available at the SNL Offshore Wind website [17]. To achieve performance criteria for these very large blades and to reduce overall blade weight and cost, studies leading to the first three designs were undertaken to investigate the benefits of the use of advanced materials while the last blade design series tests sought to investigate blade geometry innovations and proposed the use of flatback airfoils. Figure 2.2 shows a comparison of three SNL $100 \mathrm{~m}$ blades and the NREL 5-MW wind turbine blade in term of mass density, flapwise stiffness, and edgewise stiffness at normalized locations along the length. Blade series SNL100-00, SNL100-02, are SNL100-03 are selected; they represent the modifications in mass density from SNL100-00 to SNL100- 


\begin{tabular}{|c|c|c|c|c|}
\hline Material & $\begin{array}{c}\text { all-glass } \\
\text { baseline blade }\end{array}$ & $\begin{array}{c}\text { carbon } \\
\text { design }\end{array}$ & $\begin{array}{c}\text { advanced core } \\
\text { material }\end{array}$ & $\begin{array}{c}\text { advanced } \\
\text { geometry }\end{array}$ \\
\hline Blade Weight $(\mathrm{kg})$ & 114,172 & 73,995 & 59,047 & 49,519 \\
\hline Span-wise CG $(\mathrm{m})$ & 33.6 & 33.1 & 31.95 & 31.55 \\
\hline Fixed-base $f_{n}(\mathrm{~Hz})$ & 0.42 & 0.49 & 0.55 & 0.49 \\
\hline
\end{tabular}

Table 2.1: Key differences between the different SNL 100 meter blade designs.

02 and in geometry going from SNL100-02 to SNL100-03. Improvements in the design characteristics are quite evident; the SNL100-03 design has at least a 56\% reduction in weight from the original SNL100-00 baseline design as can be verified from studying Fig. 2.2. Key differences between the different SNL 100-m blade designs are summarized in Table 2.1. All the blades designed for wind speed class I and turbulence category B. Detailed descriptions regarding the structural and geometrical characteristics of all these blade models can be found elsewhere. [10], [9].

The SNL100-02 blade model is used in this study along with suggested modifications to the control system for the NREL 5-MW model that address power, blade pitch, and variable speed characteristics. We should note that in an earlier study [30], the same SNL100-02 blade design was used but a taller tower was employed then. The turbine in the present study has a hub height that is $133.5 \mathrm{~m}$ above SWL compared to $146 \mathrm{~m}$ in the earlier study. Various properties of the selected turbine for the present study are presented in Table 2.2. 

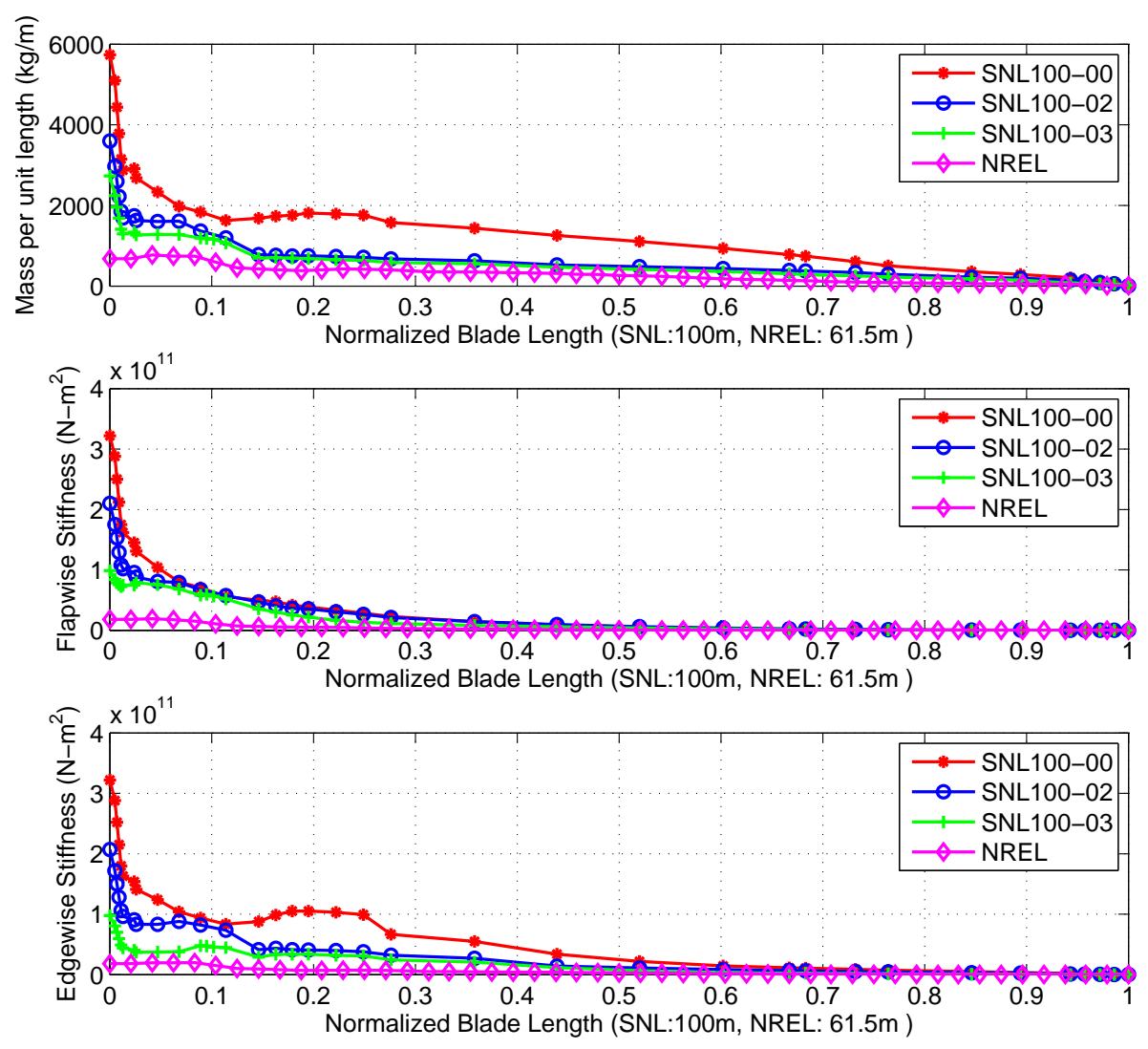

Figure 2.2: Variation in mass density, flapwise stiffness, and edgewise stiffness along the (normalized) length for three SNL 100-meter blade designs and for the NREL 5-MW wind turbine blade. 


\begin{tabular}{|c|c|c|c|}
\hline Parameter & Value & Parameter & Value \\
\hline Rated power & $13.2 \mathrm{MW}$ & Rotor orientation & upwind \\
\hline \multirow{2}{*}{ Rotor configuration } & 3 blades & Rotor diameter & $205 \mathrm{~m}$ \\
\cline { 2 - 4 } & $102.5-\mathrm{m}$ length & Hub diameter & $5 \mathrm{~m}$ \\
\hline Cut-in wind speed, $V_{\text {in }}$ & $3 \mathrm{~m} / \mathrm{s}$ & Rated wind speed & $11.3 \mathrm{~m} / \mathrm{s}$ \\
\hline Cut-out wind speed, $V_{\text {out }}$ & $25 \mathrm{~m} / \mathrm{s}$ & Hub height & $133.5 \mathrm{~m}$ \\
\hline Cut-in rotor speed & $4.34 \mathrm{rpm}$ & Rated rotor speed & $7.44 \mathrm{rpm}$ \\
\hline Generator efficiency & $94.4 \%$ & Rated tip-speed & $80 \mathrm{~m} / \mathrm{s} \mathrm{MW}$ \\
\hline Overhang & $8.16 \mathrm{~m}$ & Shaft tilt & 5 degree \\
\hline Precone & 2.5 degree & Rotor mass & $422130.688 \mathrm{~kg}$ \\
\hline Tower-top Mass & $1452130.750 \mathrm{~kg}$ & tower mass & $553994.625 \mathrm{~kg}$ \\
\hline Control system & Variable-speed generator torque, collective active pitch \\
\hline
\end{tabular}

Table 2.2: Properties of the SNL 13.2 MW wind turbine.

\subsection{Baseline Semi-submersible Platform and Mooring System}

As mentioned earlier, the OC4-DeepCwind semi-submersible platform [28] is used as the baseline model for the model development iterations; Froude scaling is applied to this model to define the semi-submersible platform model for the SNL 13.2 MW wind turbine. The OC4-DeepCwind platform is designed to be deployed in a water depth of $200 \mathrm{~m}$ and with a design draft $20 \mathrm{~m}$. The main column of the platform is connected to the tower at a location $10 \mathrm{~m}$ above the still water level (SWL). Three offset columns, whose top ends are $12 \mathrm{~m}$ above SWL, are attached to the main column through a series of smaller diameter pontoons. A schematic representation of the OC4-DeepCwind semisubmersible platform is presented in Fig. 2.3 and a summary of key geometric and structural properties of the platform is presented in Table 2.3. The mul- 


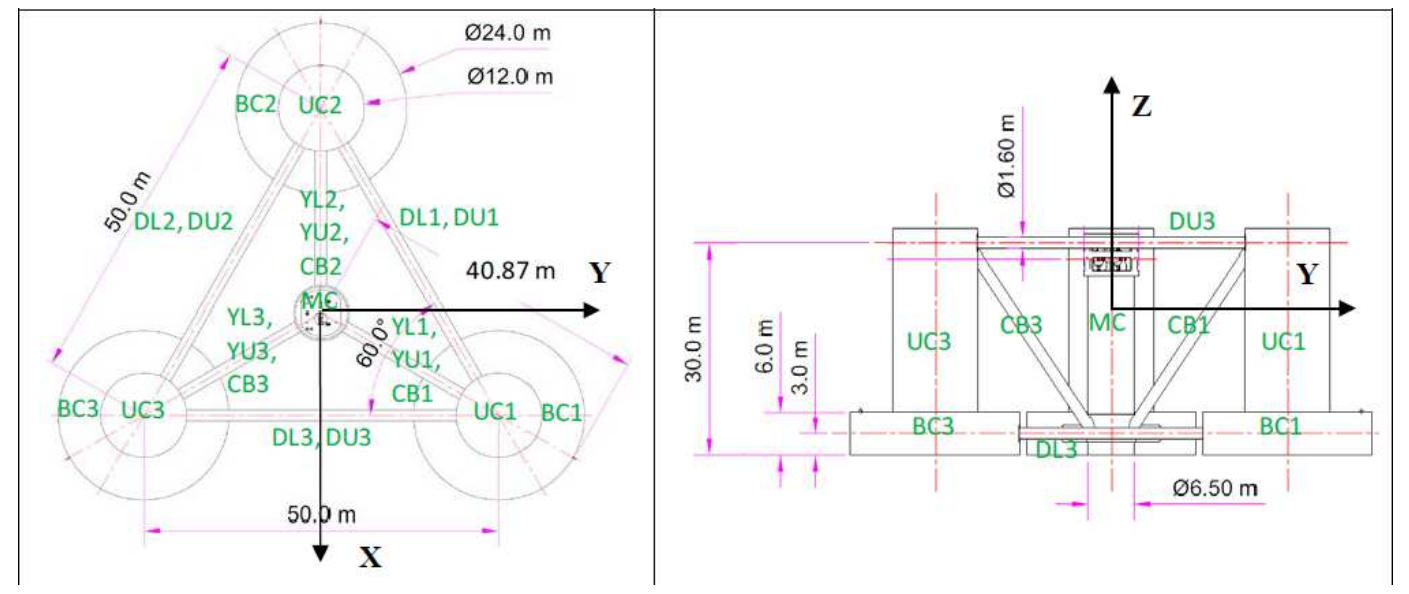

Figure 2.3: The OC4-DeepCwind semi-submersible platform: plan and elevation.

tiplication factor in the last column of the table indicates the scale factor to be applied in going from the baseline OC4 model to the proposed model based on Froude scaling law to be discussed later. Additional details related to the baseline OC4-DeepCwind semi-submersible platform model can be found elsewhere. [28].

The OC4 DeepCwind semi-submersible platform is moored by three catenary lines spread symmetrically about a vertical axis through the platform center as shown in Fig. 2.4. Anchors for the lines are fixed at the seabed at a radius of $837.6 \mathrm{~m}$ from the platform center. The lines are uniformly separated $120^{\circ}$ from each other.

We should note here that since the SNL 13.2 MW turbine and semisubmersible platform system are to be deployed at a water depth of $200 \mathrm{~m}$, which is the same as for the OC4 DeepCwind study, Froude scaling cannot be 


\begin{tabular}{|c|c|c|}
\hline Static Properties & Values & $\begin{array}{c}\text { Multiplica- } \\
\text { tion } \\
\text { factor } \\
\end{array}$ \\
\hline Depth of platform base below SWL & $20 \mathrm{~m}$ & \multirow{12}{*}{$\lambda$} \\
\hline Elevation of main column above SWL & $10 \mathrm{~m}$ & \\
\hline Elevation of offset columns above SWL & $12 \mathrm{~m}$ & \\
\hline Spacing between offset columns & $50 \mathrm{~m}$ & \\
\hline Length of upper columns & $26 \mathrm{~m}$ & \\
\hline Length of base columns & $6 \mathrm{~m}$ & \\
\hline Depth to top of base columns below SWL & $14 \mathrm{~m}$ & \\
\hline Diameter of main column & $6.5 \mathrm{~m}$ & \\
\hline Diameter of offset (upper) columns & $12 \mathrm{~m}$ & \\
\hline Diameter of base columns & $24 \mathrm{~m}$ & \\
\hline Diameter of pontoons and cross braces & $1.6 \mathrm{~m}$ & \\
\hline CM location below SWL & $13.46 \mathrm{~m}$ & \\
\hline Platform mass, including ballast & $1.3473 \mathrm{E}+7 \mathrm{~kg}$ & $\lambda^{3}$ \\
\hline Platform roll inertia about $\mathrm{CM}$ & $6.827 \mathrm{E}+9 \mathrm{~kg}-\mathrm{m}^{2}$ & \multirow{3}{*}{$\lambda^{5}$} \\
\hline Platform pitch inertia about $\mathrm{CM}$ & $6.827 \mathrm{E}+9 \mathrm{~kg}-\mathrm{m}^{2}$ & \\
\hline Platform yaw inertia about CM & $1.226 \mathrm{E}+10 \mathrm{~kg}-\mathrm{m}^{2}$ & \\
\hline
\end{tabular}

Table 2.3: The OC4-DeepCwind floating system geometry and structural properties. 
applied directly to the dimensions of the mooring system. Given the fact that even the scaled-up platform dimensions are relatively small compared to the unstretched lengths of the baseline OC4 DeepCwind mooring lines $(835.5 \mathrm{~m})$, this same unstretched length of the mooring lines is used for the SNL 13.2 MW turbine and semi-submersible platform. Other mooring system properties including the radius to the anchors and the hydrodynamic added mass and drag coefficients are also unchanged; these are indicated by (-) in the Multiplication Factor column of Table 2.4 which summarizes key mooring system properties. Figure 2.4 shows the mooring line arrangement along with the co-aligned wind and long-crested waves assumed in various analyses reported upon in this study.

\subsection{Iterations in Model Scaling}

Given the properties of the baseline turbine, tower, and platform models, iterative scaling of these models is now considered. To all linear dimensions, the same scale factor, $\lambda$, is applied to the baseline to obtain the desired model. We note that this same scaling also applies to relevant environmental conditions related to the model as well as to deformations and motions of the model [7]. Table 2.5 summarizes the scaling relationships for various physical parameters of interest.

An acceptable semi-submersible platform for the integrated system is expected to provide sufficient stability even in an unmoored state. Thus, a static analysis is first carried out to establish a suitable scale factor, $\lambda_{P}$, 


\begin{tabular}{|l|c|c|}
\hline Parameters & Values & $\begin{array}{c}\text { Multiplication } \\
\text { factor }\end{array}$ \\
\hline Number of Mooring Lines & 3 & $(-)$ \\
\hline Angle Between Adjacent Lines & 120 & $(-)$ \\
\hline Depth to Anchors Below SWL & $200 \mathrm{~m}$ & $(-)$ \\
\hline Depth to Fairleads Below SWL & $14 \mathrm{~m}$ & $\lambda_{P}$ \\
\hline Radius to Anchors from Platform Centerline & $837.6 \mathrm{~m}$ & $(-)$ \\
\hline $\begin{array}{l}\text { Radius to Fairleads from Platform } \\
\text { Centerline }\end{array}$ & $40.868 \mathrm{~m}$ & $\lambda$ \\
\hline Unstretched Mooring Line Length & $835.5 \mathrm{~m}$ & $(-)$ \\
\hline Mooring Line Diameter & $0.0766 \mathrm{~m}$ & $\lambda$ \\
\hline Equivalent Mooring Line Mass Density & $113.35 \mathrm{~kg} / \mathrm{m}$ & $\lambda^{2}$ \\
\hline Equivalent Mooring Line Mass in Water & $108.63 \mathrm{~kg} / \mathrm{m}$ & $\lambda^{2}$ \\
\hline $\begin{array}{l}\text { Equivalent Mooring Line Extensional } \\
\text { Stiffness }\end{array}$ & $753.6 \mathrm{MN}$ & $\lambda^{2}$ \\
\hline $\begin{array}{l}\text { Hydrodynamic Drag Coefficient for Mooring } \\
\text { Lines }\end{array}$ & 1.1 & $(-)$ \\
\hline $\begin{array}{l}\text { Hydrodynamic Added-Mass Coefficient for } \\
\text { Mooring Lines }\end{array}$ & 1.0 & $(-)$ \\
\hline Seabed Drag Coefficient For Mooring Lines & 1.0 & $(-)$ \\
\hline Structural Damping of Mooring Lines & $2.0 \%$ & $(-)$ \\
\hline (-) indicates parameter is not changed (relative to OC4 DeepCwind). \\
\hline
\end{tabular}

Table 2.4: Mooring system properties. 


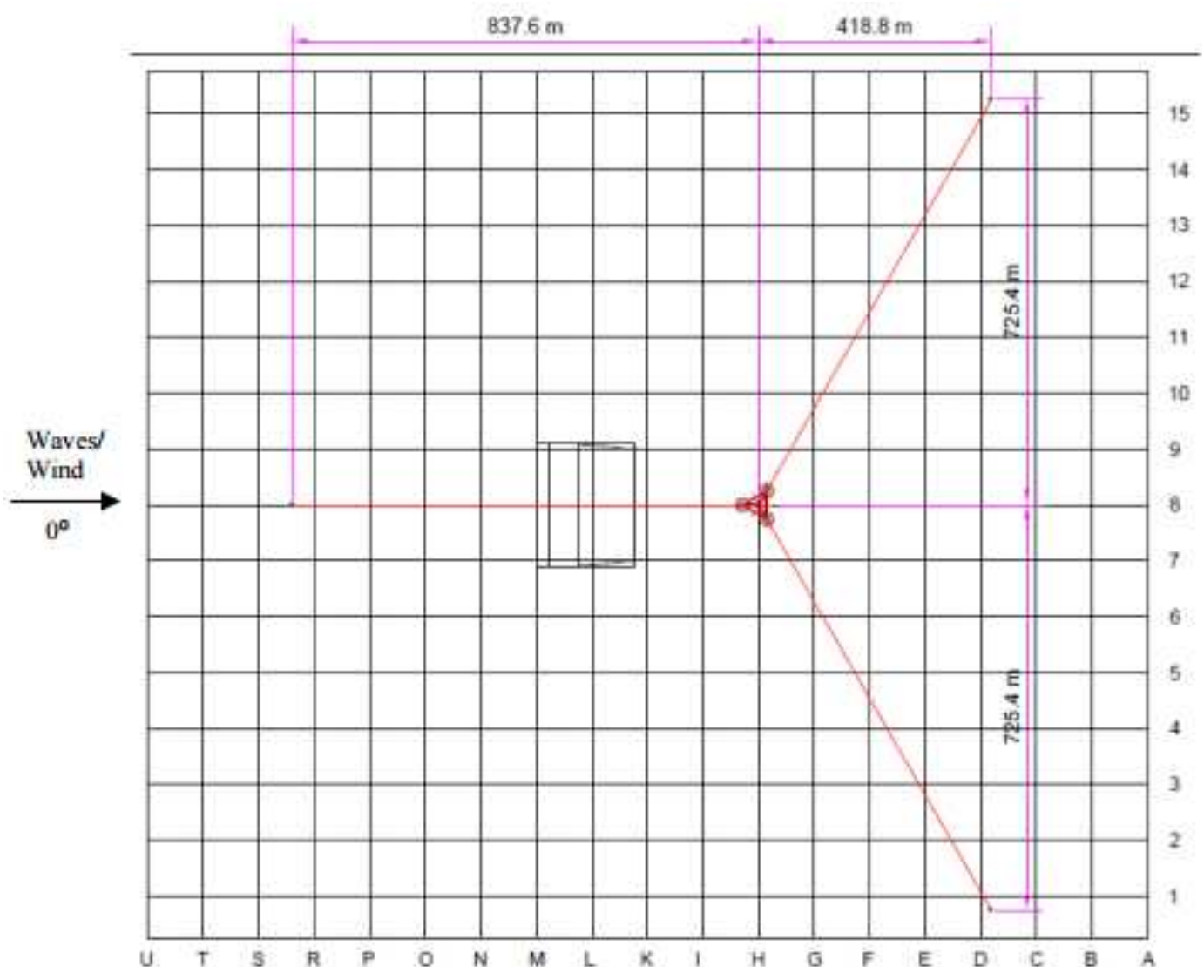

Figure 2.4: Mooring line arrangement. 
to be applied to the baseline platform. In this study, we assume that the selected dimensions for the platform geometry will be those that limit two key displacements-namely, the steady-state heave and pitch - of the integrated system to specified threshold levels. The system must experience an acceptably low steady-state pitch angle in a critical wind loading conditions (say, around the rated wind speed) that it might experience during operation. Additionally, the design draft should be adequate to provide sufficient heave stability under static and steady state conditions.

For any platform degree of freedom, the steady state motion is determined by the force on the system and the system's restoring properties (stiffness) for that corresponding motion. Thus, we have:

$$
\zeta=\frac{F}{C}
$$

where $\zeta$ is the displacement or rotation of interest, $F$ is the relevant force or moment, and $C$ is the corresponding restoring property (analogous to stiffness or resistance to the motion). We note here that to limit motions $(\zeta)$, larger values of $C$ will help but these usually arise from scaling up the baseline model, which also increases the forces, $F$.

We first consider pitch motions and associated stability. At rated wind speed, the steady-state out-of-plane tower-base bending moments are calculated for the following three land-based models:

1. NREL 5MW : NREL $5 \mathrm{MW}$ land-based reference wind turbine model, hub height $90.0 \mathrm{~m}$ 
2. SNL14602 : SNL 13.2 MW land-based wind turbine model with SNL10002 blades, hub height $146.0 \mathrm{~m}$

3. SNL13302 : SNL 13.2 MW land-based wind turbine model with SNL10002 blades, hub height $133.5 \mathrm{~m}$

If we assume a $10^{\circ}$ limit on pitch motion for satisfactory performance, the required restoring, $C_{55}^{r}$, for this motion may be found using Eq. 2.1 for any platform model and associated forcing, $F$, computed using the chosen scaling. The available static restoring coefficient, $C_{55}^{\lambda_{P}}$, for any scale factor may be derived using a Froude scaling table. Coefficients for any trial model can thus be computed by applying appropriate scale factors to the corresponding restoring coefficients for the OC4 DeepCwind platform.

Table 2.6 summarizes pitch-related results for several platform models for the SNL 13.2 MW turbine; the NREL 5-MW turbine is also included for comparison. In this table, $R$ is the ratio of the platform restoring capability, $C_{55}^{\lambda_{P}}$, to the required restoring, $C_{55}^{r}$, i.e., $R=C_{55}^{\lambda_{P}} / C_{55}^{r}$. Note that $C_{55}^{\lambda_{P}}$ is almost 2.5 times larger than $C_{55}^{r}$ with an earlier model [30] developed for the SNL 13.2 MW turbine, which implies that that model with a scale factor, $\lambda_{P}$, of 1.8 (relative to the model for the NREL 5MW turbine) is significantly overdesigned from a pitch stability perspective. This ratio is even larger for the SNL13302 model with $\lambda_{P}=1.8$. Among the tested scale factors to be used with the SNL13302 land-based model, scale factors of 1.4 and 1.5 lead to pitch motions that are in a reasonable range. Note that $R$ is not chosen too close to 
unity to allow for some margin in pitch response when an offshore platform's pitch motion is considered which could enhance the moments computed using a land-based model; also, since computations are carried out for rated wind speed conditions, the margin allows for other untested cases.

The steady-state heave motion is similarly assessed to ensure that an adequate design draft is considered for the platform. To perform the heave motion evaluation, the total system mass including the tower mass and the rotor-nacelle assembly (RNA) mass are computed. The mooring system vertical drag force is also computed using the Mooring Analysis Program (MAP). The total gravity force must be balanced by the buoyancy force at the design draft. Even though the RNA mass is constant for the selected wind turbine with blades (SNL13302), any modifications made to the tower and/or mooring system will result in a change in the platform geometry, which, in turn, will require a re-design of the tower and mooring system. An iterative procedure is thus applied to arrive at a suitably converged choice for the platform, tower and mooring system geometry. Table 2.7 shows evaluations for the $13.2 \mathrm{MW}$ wind turbine model with SNL13302 blades supported on platforms with different Froude scale factors.

As can be seen from Table 2.7, a platform scale factor, $\lambda_{P}$ of 1.4 is found to be inadequate for heave stability and does not meet the desired draft for the platform. Through an iterative process, the turbine tower height is reduced from $128 \mathrm{~m}$ (corresponding to a hub height of $146 \mathrm{~m}$ ) to $118.5 \mathrm{~m}$ (corresponding to a hub height $133.5 \mathrm{~m}$ ) to achieve the heave motion stability and design draft. 
Finally, a scale factor, $\lambda_{P}$, of 1.5 is chosen for the platform and a scale factor $\lambda$, of 2.0 chosen for the mooring line diameter proves sufficient to limit heave steady-state motion.

A direct consequence of a shorter tower is a reduction in weight and hence in overall system costs. Geometric and structural properties of the selected tower are presented in Table 2.8. The tower bottom diameter is selected to match the diameter of the platform main column. The tower thickness is adjusted to attain a tower natural frequency that meets the soft-stiff dynamic requirements for resonance avoidance from the rotor rotation and blade passing frequency at all wind speeds; the selected thickness also meets buckling stability requirements. The material properties for the steel are assumed to be the same as those used for the NREL 5-MW wind turbine; the Youngs modulus is taken to be $210 \mathrm{GPa}$, the shear modulus is taken to be $80.8 \mathrm{GPa}$, and the effective density of the steel is taken to be $8,500 \mathrm{~kg} / \mathrm{m}^{3}$.

In conclusion, after the first phase of the static design and analysis that involves an iterative process, the SNL 13.2 MW wind turbine with SNL13302 blades is to supported by a semi-submersible platform model with a scale factor 1.5 (relative to the OC4 baseline model), a mooring system with line diameter scaled up by a factor 2.0 and a tower structure with a hub height of $133.5 \mathrm{~m}$ above the still water level. A schematic representation of the selected integrated system is presented in Fig. 2.5. 


\begin{tabular}{|c|c|c|}
\hline Physical Parameter & Units & Scale Factor \\
\hline Length & {$[\mathrm{m}]$} & $\lambda$ \\
\hline Structural mass & {$[\mathrm{kg}]$} & $\lambda^{3}$ \\
\hline Force & {$[\mathrm{N}]$} & $\lambda^{3}$ \\
\hline Moment & {$[\mathrm{N}-\mathrm{m}]$} & $\lambda^{3}$ \\
\hline Acceleration & {$\left[\mathrm{m} / \mathrm{s}^{2}\right]$} & 1 \\
\hline Time & {$[\mathrm{s}]$} & $\sqrt{\lambda}$ \\
\hline Pressure & {$\left[\mathrm{Pa}=\mathrm{N} / \mathrm{m}^{2}\right]$} & $\lambda$ \\
\hline
\end{tabular}

Table 2.5: Froude scaling used in the model development.

\begin{tabular}{|c|c|c|c|c|c|c|}
\hline Model & $F_{5}(\mathrm{kN}-\mathrm{m})$ & $C_{55}^{r}(\mathrm{kN}-\mathrm{m} / \mathrm{rad})$ & $C_{55}^{\lambda_{P}}(\mathrm{kN}-\mathrm{m} / \mathrm{rad})$ & $R$ & $\lambda_{P}$ & Remarks \\
\hline NREL 5MW & $5.27 \mathrm{E}+04$ & $3.02 \mathrm{E}+05$ & $3.80 \mathrm{E}+05$ & 1.26 & 1 & $(-)$ \\
\hline \multirow{2}{*}{ SNL14602 } & \multirow{2}{*}{$2.81 \mathrm{E}+05$} & \multirow{2}{*}{$1.61 \mathrm{E}+06$} & $3.99 \mathrm{E}+06$ & 2.48 & 1.8 & Ref. [30] \\
\hline & & & $1.46 \mathrm{E}+06$ & 0.91 & 1.4 & $R<1$, fails \\
\hline \multirow{3}{*}{ SNL13302 } & \multirow{3}{*}{$2.29 \mathrm{E}+05$} & \multirow{3}{*}{$1.31 \mathrm{E}+06$} & $3.99 \mathrm{E}+06$ & 3.03 & 1.8 & $\begin{array}{c}R \gg 1, \\
\text { over-designed }\end{array}$ \\
\hline & & & $1.92 \mathrm{E}+06$ & 1.46 & 1.5 & $R>1, \mathrm{OK}$ \\
\hline & & & $1.46 \mathrm{E}+06$ & 1.11 & 1.4 & $R>1, \mathrm{OK}$ \\
\hline \multicolumn{3}{|c|}{$F_{5}$ : tower-base out-of-plane bending moment; } & \multicolumn{2}{|l|}{$R=C_{55}^{\lambda_{P}} / C_{55}^{r}$} & & \\
\hline
\end{tabular}

Table 2.6: Alternative models and evaluations against pitch motion criteria.

\begin{tabular}{|c|c|c|c|}
\hline & \multicolumn{3}{|c|}{ SNL13302 } \\
\hline Scale factor & 1.6 & 1.5 & 1.4 \\
\hline Total Mass $(\mathrm{kg})$ & $2.46 \mathrm{E}+06$ & $2.02 \mathrm{E}+06$ & $1.65 \mathrm{E}+06$ \\
\hline Allowable Tower Mass, $C(\mathrm{~kg})$ & $1.00 \mathrm{E}+06$ & $5.72 \mathrm{E}+05$ & $1.94 \mathrm{E}+05$ \\
\hline Actual Tower Mass, $D(\mathrm{~kg})$ & $5.86 \mathrm{E}+05$ & $5.54 \mathrm{E}+05$ & $5.21 \mathrm{E}+05$ \\
\hline Remarks & $D \ll C$, over-designed & $C \simeq D$ OK & $D \gg C$, fails \\
\hline
\end{tabular}

Table 2.7: Alternative models and evaluations against heave motion criteria. 


\begin{tabular}{|c|c|c|c|c|c|c|c|c|}
\hline Elevation & HtFract & TMassDen & TwFAStif & TwSSStif & TwGJStif & TwEAStif & TwFAIner & TwSSIner \\
\hline$(\mathrm{m})$ & $(-)$ & $(\mathrm{kg} / \mathrm{m})$ & $\left(\mathrm{N}-\mathrm{m}^{2}\right)$ & $\left(\mathrm{N}-\mathrm{m}^{2}\right)$ & $\left(\mathrm{N}-\mathrm{m}^{2}\right)$ & $(\mathrm{N})$ & $(\mathrm{kg}-\mathrm{m})$ & $(\mathrm{kg}-\mathrm{m})$ \\
\hline 0.00 & 0.0 & 7010.24 & $2.05 \mathrm{E}+12$ & $2.05 \mathrm{E}+12$ & $1.57 \mathrm{E}+12$ & $1.73 \mathrm{E}+11$ & 82841.3 & 82841.3 \\
\hline 11.46 & 0.1 & 6527.08 & $1.75 \mathrm{E}+12$ & $1.75 \mathrm{E}+12$ & $1.35 \mathrm{E}+12$ & $1.61 \mathrm{E}+11$ & 71011.8 & 71011.8 \\
\hline 22.92 & 0.2 & 6060.75 & $1.49 \mathrm{E}+12$ & $1.49 \mathrm{E}+12$ & $1.15 \mathrm{E}+12$ & $1.5 \mathrm{E}+11$ & 60490.5 & 60490.5 \\
\hline 34.38 & 0.3 & 5611.23 & $1.26 \mathrm{E}+12$ & $1.26 \mathrm{E}+12$ & $9.73 \mathrm{E}+11$ & $1.39 \mathrm{E}+11$ & 51177.7 & 51177.7 \\
\hline 45.84 & 0.4 & 5178.54 & $1.06 \mathrm{E}+12$ & $1.06 \mathrm{E}+12$ & $8.17 \mathrm{E}+11$ & $1.28 \mathrm{E}+11$ & 42977.8 & 42977.8 \\
\hline 57.30 & 0.5 & 4762.67 & $8.84 \mathrm{E}+11$ & $8.84 \mathrm{E}+11$ & $6.81 \mathrm{E}+11$ & $1.18 \mathrm{E}+11$ & 35799.1 & 35799.1 \\
\hline 68.76 & 0.6 & 4363.62 & $7.30 \mathrm{E}+11$ & $7.30 \mathrm{E}+11$ & $5.62 \mathrm{E}+11$ & $1.08 \mathrm{E}+11$ & 29553.6 & 29553.6 \\
\hline 80.22 & 0.7 & 3981.39 & $5.97 \mathrm{E}+11$ & $5.97 \mathrm{E}+11$ & $4.59 \mathrm{E}+11$ & $9.84 \mathrm{E}+10$ & 24157.5 & 24157.5 \\
\hline 91.68 & 0.8 & 3615.98 & $4.83 \mathrm{E}+11$ & $4.83 \mathrm{E}+11$ & $3.71 \mathrm{E}+11$ & $8.93 \mathrm{E}+10$ & 19530.8 & 19530.8 \\
\hline 103.14 & 0.9 & 3267.39 & $3.85 \mathrm{E}+11$ & $3.85 \mathrm{E}+11$ & $2.97 \mathrm{E}+11$ & $8.07 \mathrm{E}+10$ & 15597.3 & 15597.3 \\
\hline 114.60 & 1.0 & 2935.63 & $3.04 \mathrm{E}+11$ & $3.04 \mathrm{E}+11$ & $2.34 \mathrm{E}+11$ & $7.25 \mathrm{E}+10$ & 12284.9 & 12284.9 \\
\hline
\end{tabular}

Table 2.8: Distributed Geometric and Structural Properties for the $115.6 \mathrm{~m}$ Tower for the SNL 13.2 MW Wind Turbine. 


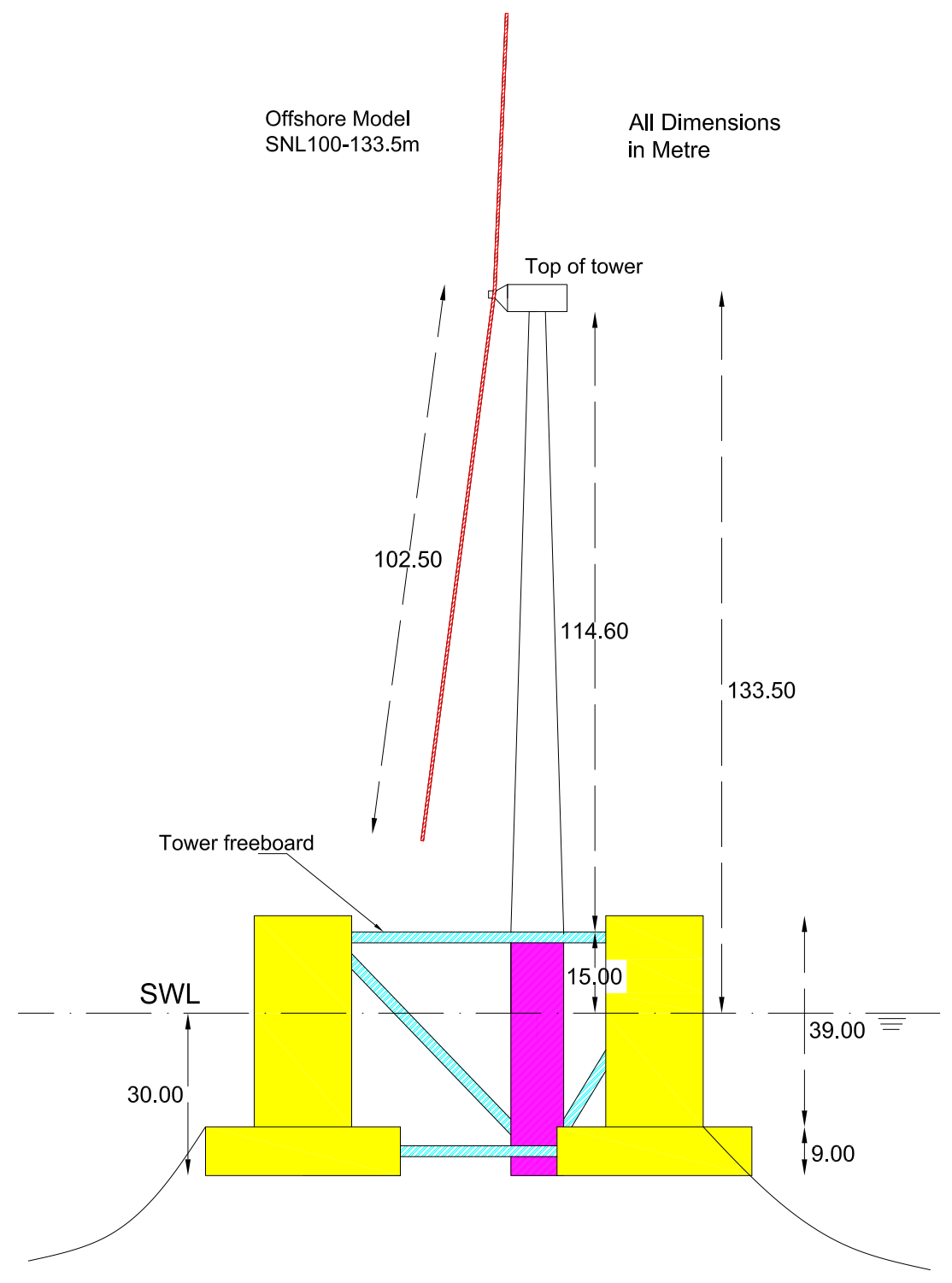

Figure 2.5: Integrated system showing Sandia 13.2 MW wind turbine, tower, semi-submersible floating platform, and mooring lines. 


\section{Chapter 3}

\section{Properties of Final Wind Turbine and Semi-submersible Platform}

To perform integrated system dynamic response simulations in FAST, the dynamic properties of the structure must be provided as input to the ElastoDyn and HydroDyn modules in FAST. In this chapter, we discuss the computation of mode shapes for the tower and verify that a soft-stiff design is achieved with the selected wind turbine tower. Additionally, hydrodynamic properties of the platform are obtained based on potential flow theory using WAMIT and its use is justified.

\subsection{Tower Dynamic Properties}

In order to carry out dynamic response simulation, mode shapes for the tower of the integrated system must be computed and then implemented into the FAST model. The first two mode shapes of the tower are calculated using BModes, a finite-element code developed at NREL that provides dynamically coupled modes for beam members; these mode shapes are presented in Fig. 3.1. In the computation of these mode shapes, the tower is assumed to be cantilevered at the base and the tower top mass is assumed to be a point mass 
acting at the top of the tower at some distance offset from the rotor plan.

One of the primary considerations in the tower design is the overall tower stiffness, which also has a direct effect on its natural frequency. We seek here to meet the soft-stiff dynamic design requirement with the selected tower. Analysis of the tower model is required to ensure that no natural mode resonances are excited by any motions in the rest of the turbine [21]. Resonance-induced loads arising as a result of rotor operation and the tower's natural frequency are discussed here. A Campbell diagram is developed here to identify any such undesired resonance arising from interaction of the system natural frequencies and rotor rotation rates.

FAST v7 has the capability of extracting linearized representations of the complete nonlinear system. The following two steps are involved in the process: (1) computation of a periodic steady-state operating point condition for the degrees of freedom; and (2) linearization of the FAST model about this operating point so as to form periodic state matrices [14]. Uniform wind speed is required to start the linearization analysis. The rotor collective blade pitch is trimmed to reach the desired azimuth-averaged rotor speed condition. Multi-blade coordinate transformation is performed before taking the azimuth average to avoid scenarios where the linear model exhibits periodicity (i.e., the model is linearized with a spinning rotor).

As shown in Fig. 3.2, a number of system natural frequencies including the first and second tower fore-aft and side-side frequencies as well as the first and second blade frequencies are plotted as a function of rotor speed. The 

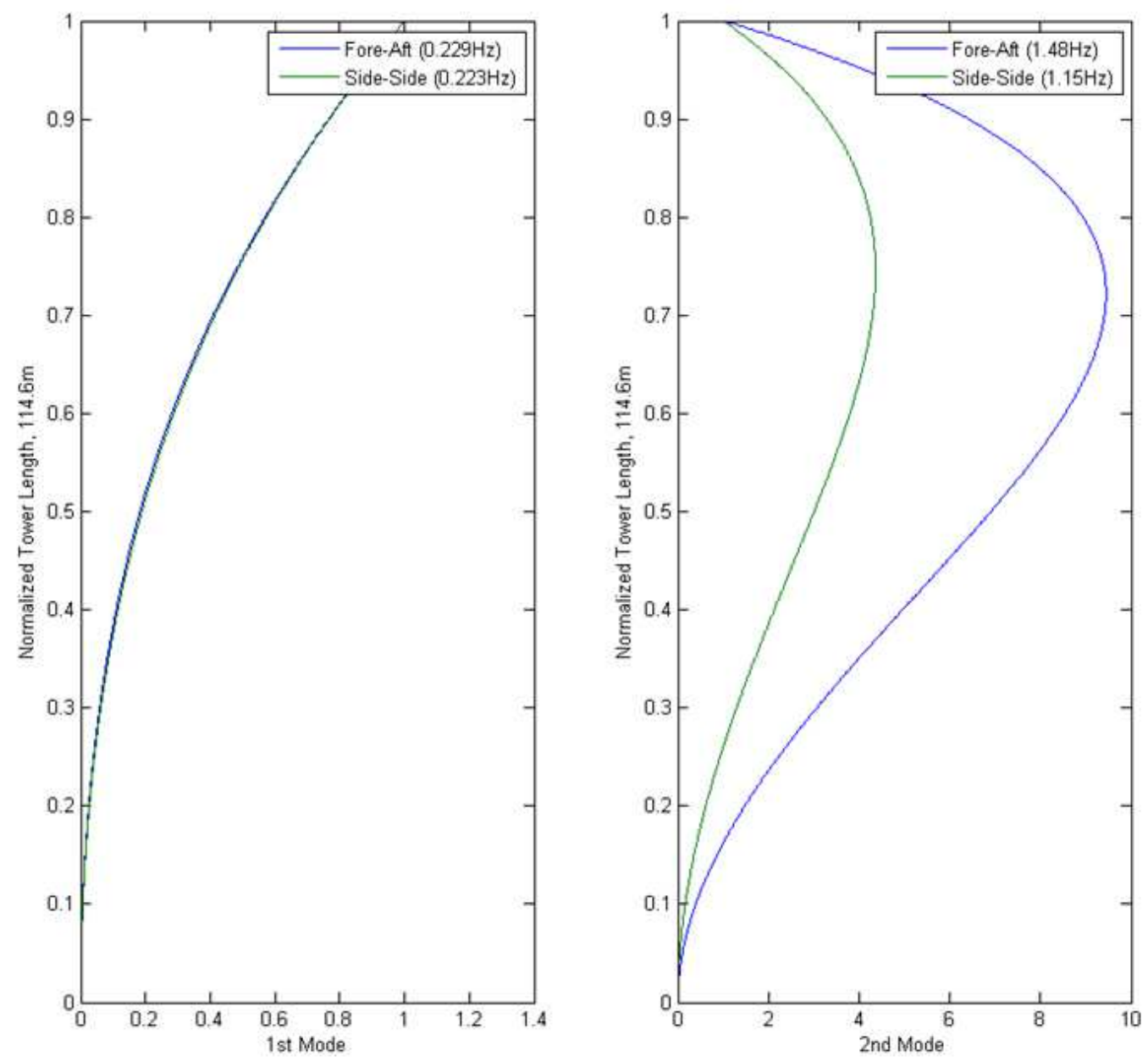

Figure 3.1: First two tower mode shapes. 


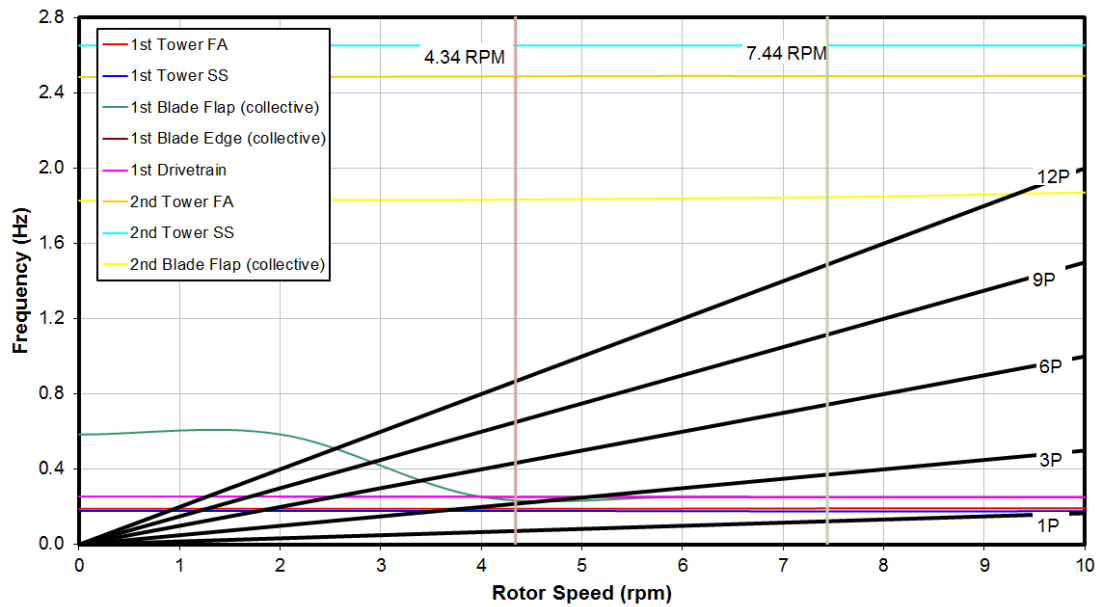

Figure 3.2: Campbell diagram for the SNL $13.2 \mathrm{MW}$ wind turbine with SNL100-02 blades and a $118.5 \mathrm{~m}$ tower.

results show that the blade natural frequencies are more sensitive than the support structure to the rotor speed at the starting range (lowest levels) from $0 \sim 4.34 \mathrm{rpm}$ (cut-in rotor speed). Over a range of operating rotor speeds (4.34 rpm to $7.44 \mathrm{rpm})$, most of the frequencies are able to avoid the rotor rotation frequency $(1 \mathrm{P})$ and the blade passing frequency (3P) except for the first drivetrain frequencies at rotor rotation rates of around $5 \mathrm{rpm}$. This is not of concern since we are dealing only with the wind turbine tower design.

\subsection{Platform Hydrodynamic Properties}

Generally speaking, hydrodynamic loads on offshore structures include contributions from inertia (added mass), linear drag (radiation), buoyancy (restoring), incident-wave scattering (diffraction), sea currents, and nonlinear 
effects. To the HydroDyn module within FAST, one needs to provide hydrostatic restoring, added-mass, and damping contributions from linear wave radiation, including free-surface memory effects, incident-wave excitation from linear diffraction in regular or irregular seas, and also nonlinear viscous drag from incident-wave kinematics, sea currents, and platform motions. In this study, WAMIT is used to obtain required linear hydrodynamic coefficients; the HydroDyn module in FAST accounts for the viscous drag forces. Some background related to hydrodynamics and the HydroDyn module in the context of problems such as the one in this work are discussed in other studies. [7], [13], [25]

\subsubsection{Keulegan-Carpenter number: Flow-Structure Interaction}

When potential flow theory is used to calculate diffraction forces, there is an assumption that no flow separation occurs. For cylindrical structures such as the columns of the semi-submersible platform in the present study, flow separation will occur when the Keulegan-Carpenter (KC) number exceeds 2. The $\mathrm{KC}$ number is a dimensionless parameter that describes the relative importance of the drag forces over inertia forces for an object in an oscillatory fluid flow; it is defined as follows:

$$
K C=\frac{u T}{D}
$$

where, $D$ is the cylinder diameter, $T$ is the wave period, and $u$ is the amplitude of the fluid velocity normal to the cylinder. 
Generally, for a vertical cylinder with a large diameter, flow separation occurs only in (i) the upper section of the cylinder, because of the larger fluid particle velocities closer to the surface; or (ii) in extreme sea states because of the associated longer wave period, $T$. As demonstrated in the OC4 study [28], the $\mathrm{KC}$ number is less than 2 for the large components of the OC4 DeepCwind semi-submersible platform for almost all sea states except for extreme wave conditions (such as the Normal sea states 6-8 defined in Table 3.1). For these same sea states, we find that potential flow theory is more widely applicable for the 1.5-scaled SNL platform model than was the case for the OC4 DeepCwind platform (refer to Figures 3.3(a) and 3.3(b)). This is because of the increased dimensions of our scaled-up platform. In Figures 3.3(c) and 3.3(d), we observe that even for very severe sea states [31] that are considered with the SNL model in a related study, the $\mathrm{KC}$ numbers are less than 2 in all the sea states for the offset columns whereas for the main column, in only two of the sea states show a $\mathrm{KC}$ value of greater than 2. Hence, for all but the most severe sea states, the use of potential flow theory to obtain hydrodynamic coefficients can be justified. In a few extreme cases, flow separation becomes more important and, then, Morison's equation will have to be utilized. The use of Morison's equation permits us to include viscous drag forces that are generated due to incident wave kinematics and platform motions. 


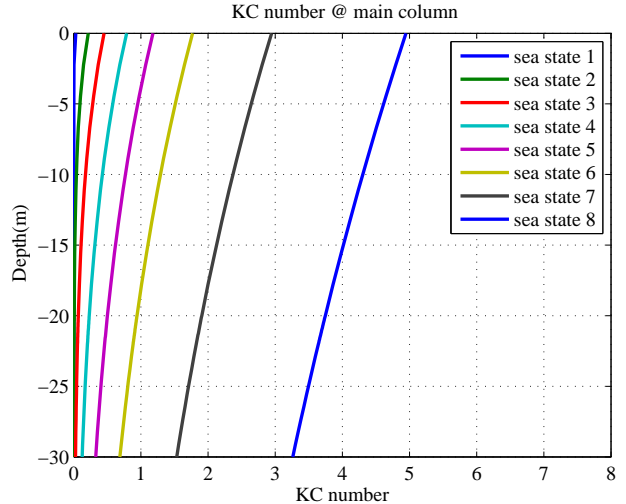

(a) KC number for main column at normal sea states

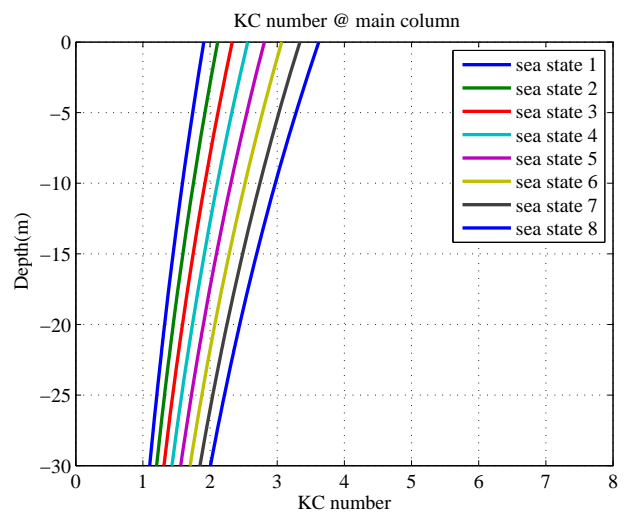

(c) $\mathrm{KC}$ number for main column at 50 year return sea states

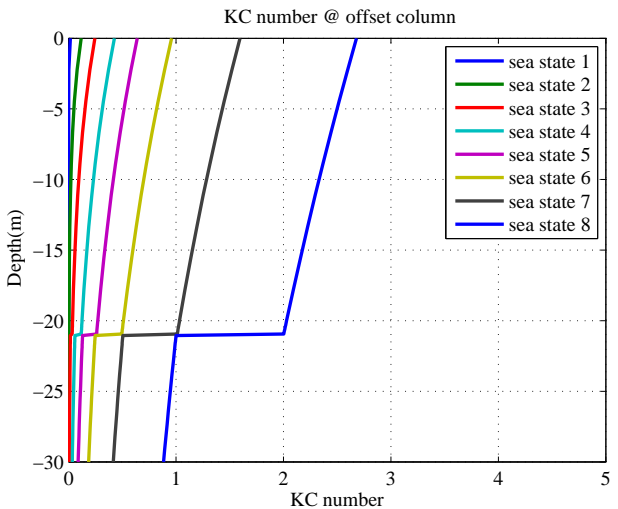

(b) KC number for offset column at normal sea states

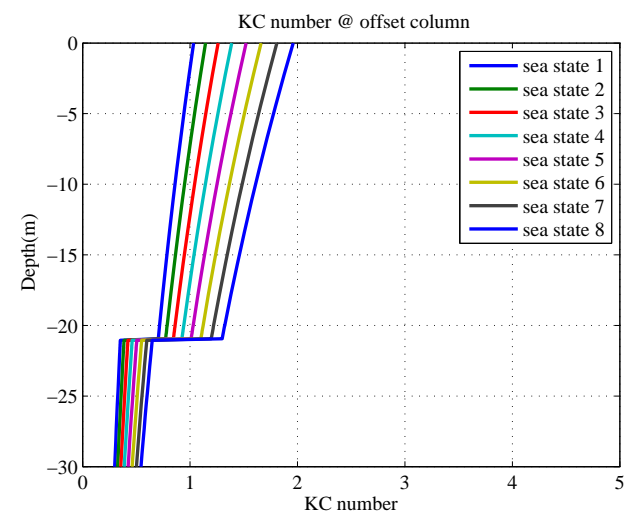

(d) $\mathrm{KC}$ number for offset column at 50 year return sea states

Figure 3.3: KC numbers for the SNL semi-submersible platform. 


\begin{tabular}{|c|c|c|c|c|}
\hline & \multicolumn{2}{|c|}{ Normal } & \multicolumn{2}{c|}{50 -year return } \\
\hline Sea States & $T(\mathrm{~s})$ & $H_{s}(\mathrm{~m})$ & $T(\mathrm{~s})$ & $H_{s}(\mathrm{~m})$ \\
\hline 1 & 2.0 & 0.09 & 14.83 & 5.91 \\
2 & 4.8 & 0.67 & 14.65 & 6.55 \\
3 & 6.5 & 1.40 & 14.51 & 7.22 \\
4 & 8.1 & 2.44 & 14.41 & 7.94 \\
5 & 9.7 & 3.66 & 14.35 & 8.71 \\
6 & 11.3 & 5.49 & 14.32 & 9.51 \\
7 & 13.6 & 9.14 & 14.3 & 10.35 \\
8 & 17.0 & 15.24 & 14.31 & 11.52 \\
\hline
\end{tabular}

Table 3.1: Sea states defined by wave spectral peak period, $T$, and significant wave height, $H_{s}$, selected for the dynamic analyses.

\subsubsection{MultiSurf: Platform Model Geometry}

Since WAMIT is a code based on the panel method, the platform model is discretized into flat panels using a 3D computer-aided design (CAD) tool, MultiSurf. To improve the accuracy of the WAMIT results, a high-order representation of all geometric descriptions is desired. MultiSurf has the capability of achieving this and models are easily exported directly to WAMIT. The advantages of a high-order analysis over a low-order analysis is that in the high-order representation, source and dipole densities over parameteric surface patches are represented by B-spline distributions while in low-order analysis, those densities are assumed to be constant. Hence, more accurate geometric models as well as simulation results are possible with a high-order analysis. A MultiSurf model of the platform using a discretization with 53,760 panels is shown in Figure 3.4. A typical size of a panel element is $2 \mathrm{~m}$ and meshes around connections between members are more refined. Taking advantage of 

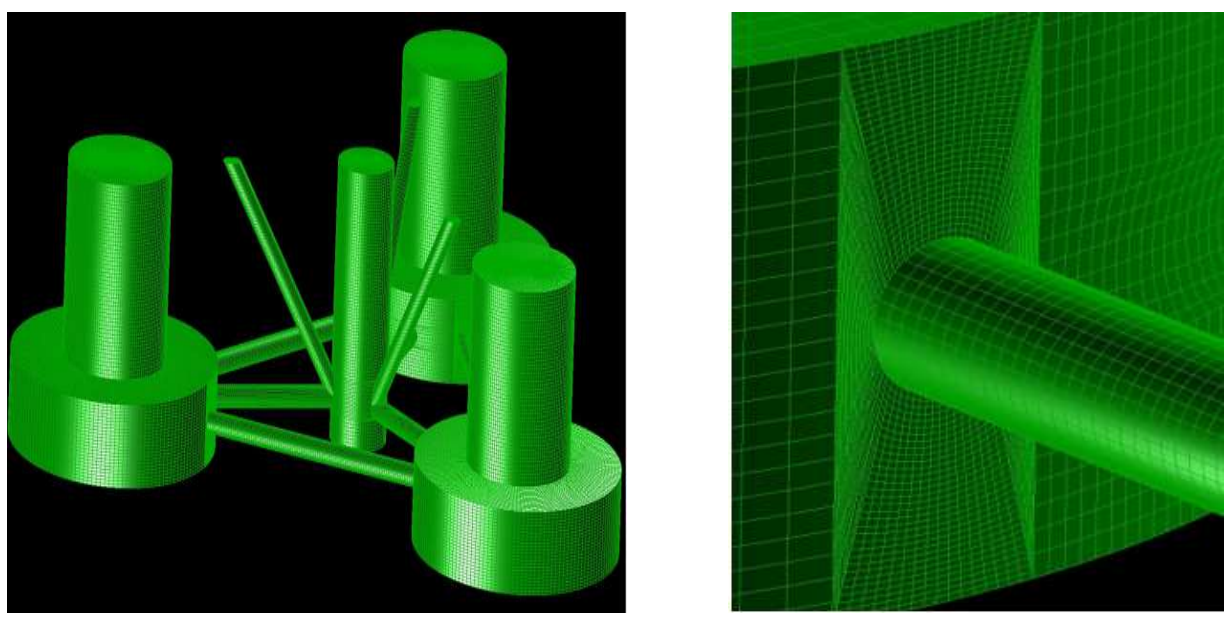

Figure 3.4: MultiSurf model of the SNL semi-submersible platform.

symmetry about the $x$-axis, only half of the platform is used in developing the platform model.

\subsubsection{WAMIT: Potential Flow Theory}

As was demonstrated above, potential flow theory is generally valid with the SNL model for most sea states. The linear hydrodynamic radiation and diffraction problems are thus solved using WAMIT. Radiation-induced added mass $A_{i j}(\omega)$ and damping $\left.B_{(i j}\right)(\omega)$ matrices are given as a function of frequency, $\omega(\mathrm{rad} / \mathrm{s})$, as shown in Fig. 3.5. Due to the absence of forward speed, the added mass and damping matrix are symmetric. In addition, $A_{11}$ and $B_{11}$ are identical to $A_{22}$ and $B_{22}$ because of the symmetric properties of the SNL semi-submersible platform; a similar relationship exists for $A_{44}, B_{44}$, and $A_{55}, B_{55}$. The infinite-frequency added-mass matrix $A_{\infty}$, is as follows: 


$$
A_{\infty}=\left|\begin{array}{cccccc}
2.95 E+07 & 0 & 0 & 0 & -5.44 E+08 & 0 \\
0 & 2.95 E+07 & 0 & 5.44 E+08 & 0 & 0 \\
0 & 0 & 5.04 E+07 & 0 & 0 & 0 \\
0 & 5.44 E+08 & 0 & 5.79 E+10 & 0 & 0 \\
-5.45 E+08 & 0 & 0 & 0 & 5.79 E+10 & 0 \\
0 & 0 & 0 & 0 & 0 & 4.88 E+10
\end{array}\right|
$$

Figure 3.7 shows amplitude and phase values of the hydrodynamic wave-excitation vector from the linear diffraction problem as a function of frequency resulting from incident waves at zero wave heading (i.e., in the surge direction). Because of the selected direction of the incident waves, loads in the direction of sway (Mode 2), roll (Mode 4), and yaw (Mode 6) DOFs are zero because the wave forces are in the $X-Z$ plane. The infinite-frequency limit is zero for all the force coefficients.

\subsubsection{HydroDyn: Morsion's Equation}

As mentioned earlier, if the $\mathrm{KC}$ number exceeds 2, potential flow theory is no longer valid. Flow separation becomes more important in this case and can lead to viscous drag forces on the platform. In HydroDyn, this is accounted

for by including the nonlinear viscous drag term, $\frac{1}{2} C_{d} \rho D(u-\dot{q})|u-\dot{q}|$, in Morison's equation (where $C_{d}$ is a drag coefficient, $\rho$ is the density of water, $D$ is the body diameter, $u$ is the water particle velocity, and $\dot{q}$ is the structural velocity). The drag coefficient, $C_{d}$, is a function of Reynold's number, which could vary greatly across the flow regimes for each structural member. In the design of the OC4 platform, an average $C_{d}$ value was calculated for each 

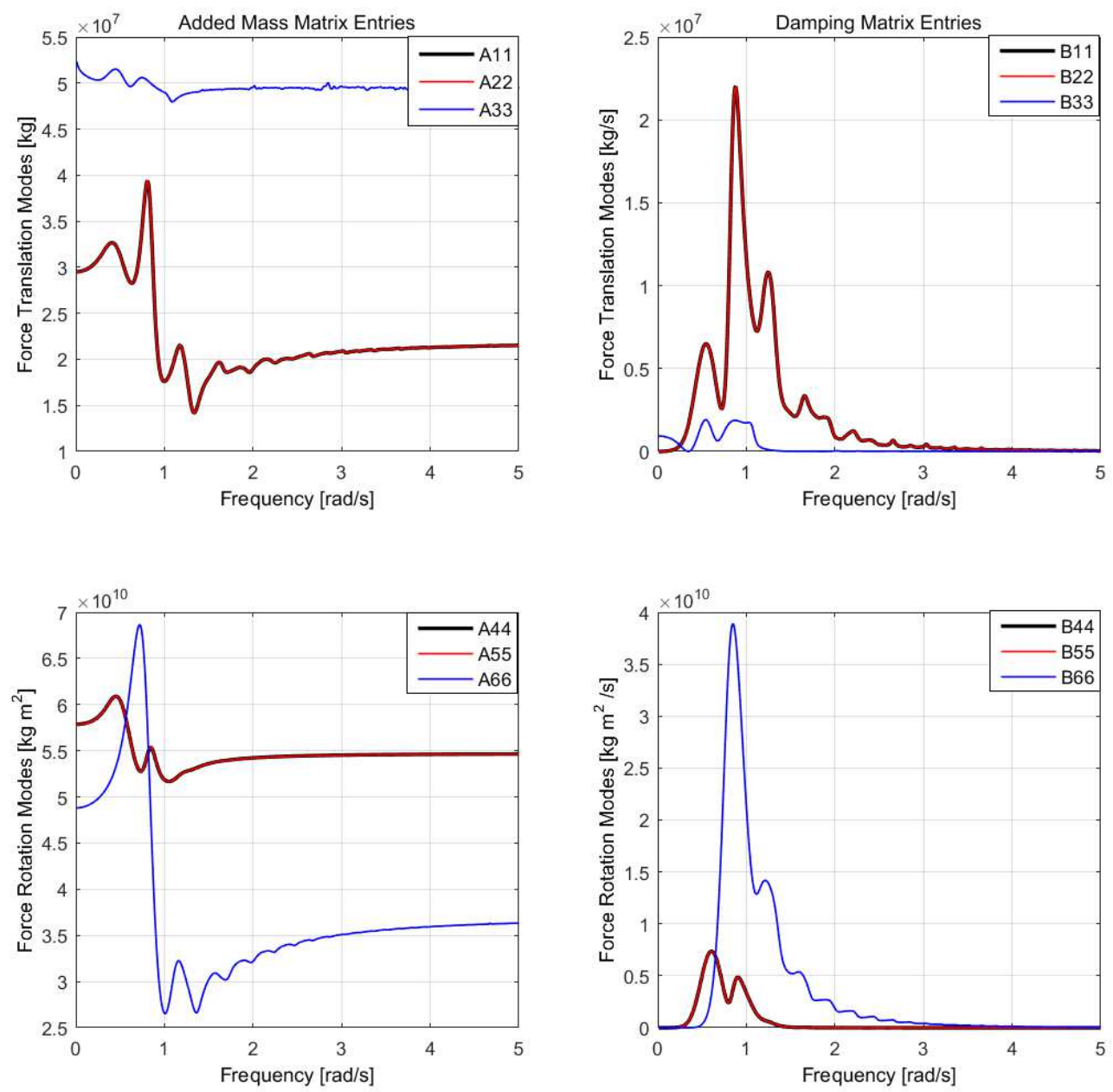

Figure 3.5: SNL semi-submersible platform added mass and damping coefficients for a zero wave heading. 

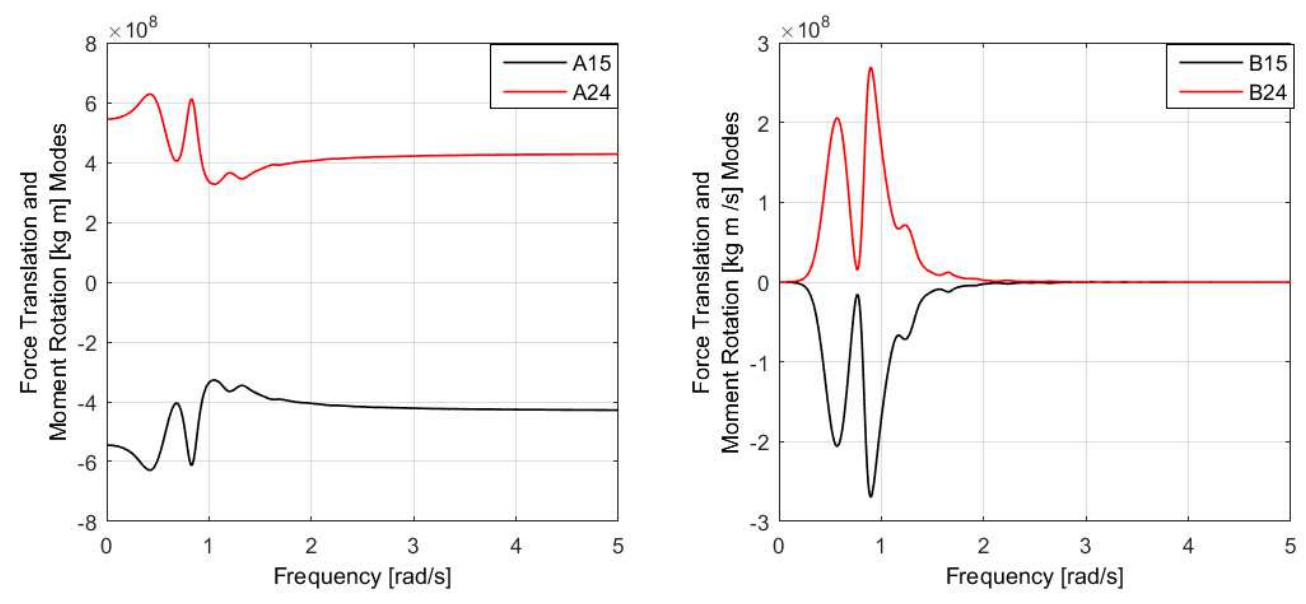

Figure 3.6: SNL semi-submersible platform added mass and damping coefficients for a zero wave heading.
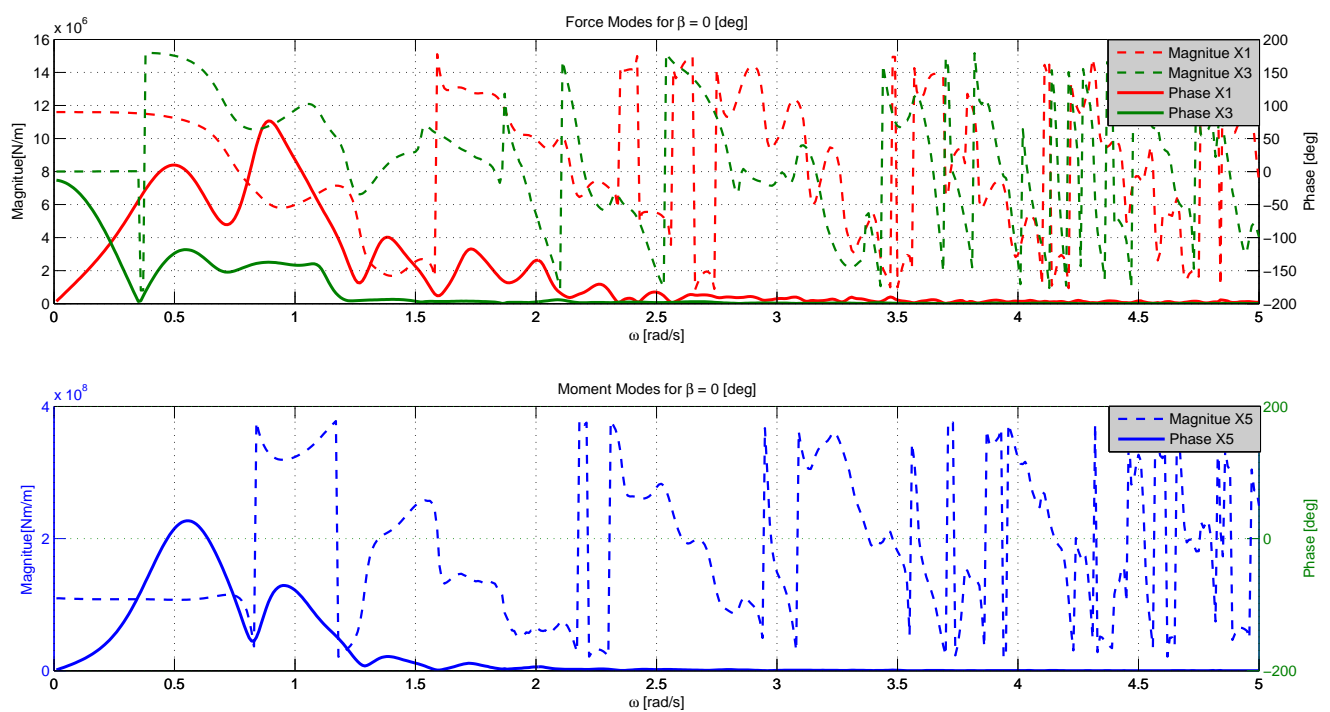

Figure 3.7: SNL semi-submersible platform excitation force coefficients for a zero wave heading. 


\begin{tabular}{|c|c|}
\hline Coefficients & Value \\
\hline Water depth $(h)$ & $200 \mathrm{~m}$ \\
\hline Displaced water in undisplaced position $\left(V_{0}\right)$ & $46969.8 \mathrm{~m}^{3}$ \\
\hline Buoyancy force in undisplaced position $\left(\rho g V_{0}\right)$ & $1.3989 \mathrm{E}+8 \mathrm{~N}$ \\
\hline Hydrostatic restoring in heave $\left(C_{33}^{\text {Hydrostatic }}\right)$ & $8.59+06 \mathrm{~N} / \mathrm{m}$ \\
\hline Hydrostatic restoring in roll $\left(C_{44}^{\text {Hydrostatic }}\right)$ & $-1.927 \mathrm{E}+09 \mathrm{Nm} / \mathrm{rad}$ \\
\hline Hydrostatic restoring in pitch $\left(C_{55}^{\text {Hydrostatic }}\right)$ & $-1.927 \mathrm{E}+09 \mathrm{Nm} / \mathrm{rad}$ \\
\hline Added-mass coefficient $\left(C_{a}\right)$ for all members & 0.63 \\
\hline $\begin{array}{l}\text { Added-mass coefficient }\left(C_{a z}\right) \text { for the base column in } \\
\text { the } z \text { direction }\end{array}$ & 1.0 \\
\hline Drag coefficient $\left(C_{d}\right)$ for the main column & 0.56 \\
\hline Drag coefficient $\left(C_{d}\right)$ for the upper columns & 0.61 \\
\hline Drag coefficient $\left(C_{d}\right)$ for the base columns & 0.68 \\
\hline $\begin{array}{l}\text { Drag coefficient }\left(C_{d}\right) \text { for the pontoons and cross } \\
\text { members }\end{array}$ & 0.63 \\
\hline $\begin{array}{l}\text { Drag coefficient }\left(C_{d z}\right) \text { for the base columns in the } z \\
\text { direction }\end{array}$ & 4.8 \\
\hline
\end{tabular}

Table 3.2: Floating platform hydrodynamic properties.

member, with special attention taken due to the heave plate. For the SNL model presented, averaged drag coefficients are also used and are assumed to be same as those calculated for the OC4 platform-see Table 3.2. Other hydrodynamic properties of the platform are also included in the table. 


\section{Chapter 4}

\section{Response Analysis of the Integrated System}

A final step in the iterative model development is to evaluate the static and dynamic performance of the integrated wind turbine system. Timedomain simulation are carried out for different sea states in FAST and the system response is analyzed to help understand the behavior of the integrated system. All the structural and dynamic properties of each subsystem that have been demonstrated will be implemented in the integrated system's FAST model. Environment conditions are defined by specifying assumptions on wind velocity, wave height, and wave period descriptions, without consideration of current. A series of-time domain simulation results including steady state motion offsets, response amplitude operators (RAOs), and overall performance under selected wind filed and wave conditions are discussed in this chapter.

First, steady-state motion offset evaluation is performed via free-decay simulations wherein the model is released in free vibration from specific initial conditions and any wind, wave and current inputs. To understand the system's steady-state performance, a series of time-domain simulation are carried out under uniform wind and regular wave states. Finally, dynamic response properties are studied by, first, evaluating response amplitude operators (RAOs) 
and, next, evaluating the overall system dynamic performance under turbulent wind fields and for long-crested irregular waves.

\subsection{Steady-state response analysis}

Steady-state simulations are performed using FAST under uniform wind fields without shear and for regular waves. The desired wind field can be easily generated in AeroDyn by specifying the target wind velocity; the wave height and wave period are specified in the HydroDyn module for the regular wave mode. The response of the mooring lines is captured by quasi-static analysis using Mooring Analysis Program (MAP), which is integrated in FAST. The steady-state time-domain analyses can be helpful in understanding the overall and fundamental behavior of the integrated turbine-platform-mooring system.

\subsubsection{Free-decay simulation}

Free-decay simulation is conducted in FAST by applying a specific initial platform displacement without the existence of wind, waves, and currents. AeroDyn is disabled for this purpose and the wave mode is chosen to be "still water" in HydroDyn. An initial heave motion of 2 meters is applied in this study. As can be seen from Fig. 4.1, all 6 modes stabilize with time. For surge, sway, roll, and yaw motion, the platform oscillates around zero as expected. There is a slight offset of about 0.02 meter in heave motion, which is negligible for such a large system. Pitch motions show an approximately -0.06 degree offset at steady state which could be explained by the fact that the center of 


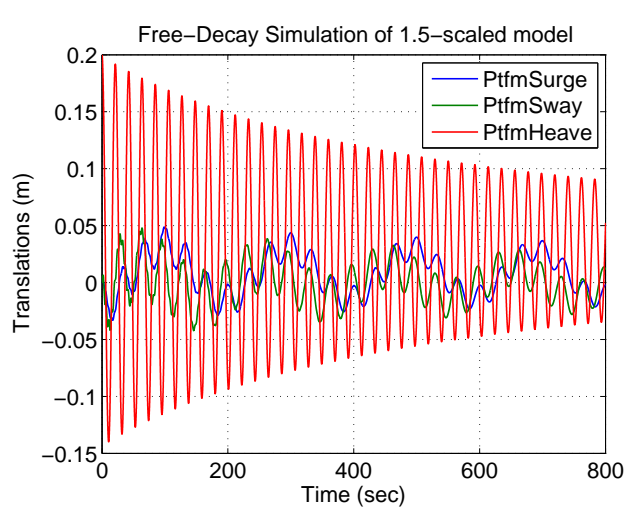

(a) Modes 1,2,3

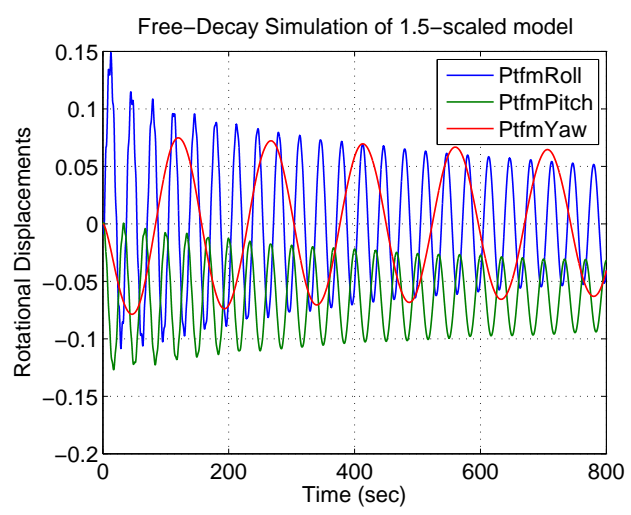

(b) Modes 4,5,6

Figure 4.1: Free-decay simulation of the integrated system model following an initial heave displacement of 2 meters.

mass $(\mathrm{CM})$ of the wind turbine is misaligned with the CM of the platform vertically. Coupling among these six modes is evident in the free-decay simulation results.

\subsubsection{Steady-state response of integrated system under uniform wind and regular waves}

Regular waves accompanied by a uniform wind field are applied next in order to study the steady-state response of the integrated system. The model is first studied at the rated wind speed and for a unit-amplitude wave. The wave frequency is chosen to match the natural frequency of the platform in surge $(0.0057 \mathrm{~Hz})$. As can be seen in Fig. 4.2, the surge and pitch motions are the most significant compared with the other four motions. Resonance response of the platform's surge motion is triggered because of the chosen wave frequency which is close to the platform's natural frequency in surge. 


\begin{tabular}{|c|c|c|c|c|c|c|}
\hline \multirow{2}{*}{$\mathrm{V}(\mathrm{m} / \mathrm{s})$} & \multicolumn{2}{|c|}{ low wave height } & \multicolumn{2}{c|}{ medium wave height } & \multicolumn{2}{c|}{ high wave height } \\
\cline { 2 - 7 } & $H_{s}(\mathrm{~m})$ & $T_{p}(\mathrm{~s})$ & $H_{s}(\mathrm{~m})$ & $T_{p}(\mathrm{~s})$ & $H_{s}(\mathrm{~m})$ & $T_{p}(\mathrm{~s})$ \\
\hline 9 & 1.0 & 7.0 & 2.5 & 8.0 & 4.0 & 9.5 \\
\hline 12 & 1.0 & 6.0 & 2.5 & 7.0 & 4.0 & 8.5 \\
\hline 16 & 2.0 & 8.0 & 3.5 & 8.5 & 5.0 & 10.5 \\
\hline
\end{tabular}

Table 4.1: Selected sea states for short-term response analysis.

Since both wind and waves are propagating only in the $x$-direction, relative small response levels in the sway and roll modes are found. Some coupling among different types of motion is evident in the time series.

The sea state studied here in a steady-state analysis, next, is based on recorded data frpom a site located close to Half Moon Bay, about 24 nautical miles south-southwest of San Francisco, California. Wind and wave data are available from National Data Buoy Center (NDBC) Station 46012 [5]. The geographical coordinates of this site are $27^{\circ} 21^{\prime} N, 122^{\circ} 52^{\prime} W$. The selected sea states in Table 4.1 are for wind speeds around the rated wind speed, where extreme response levels usually occur. Simulations of 10-min duration for each case are studied and results from these simulations presented in Table 4.2 are based on the steady-state response after transients die out. Response maximum results are not excessively large for any of the sea states; this helps in further validating the selected model in terms of pitch and heave motions.

\subsubsection{Response Amplitude Operators}

Response amplitude operators (RAOs), which represent the response of a system to a unit-amplitude periodic wave from a given direction or heading, 

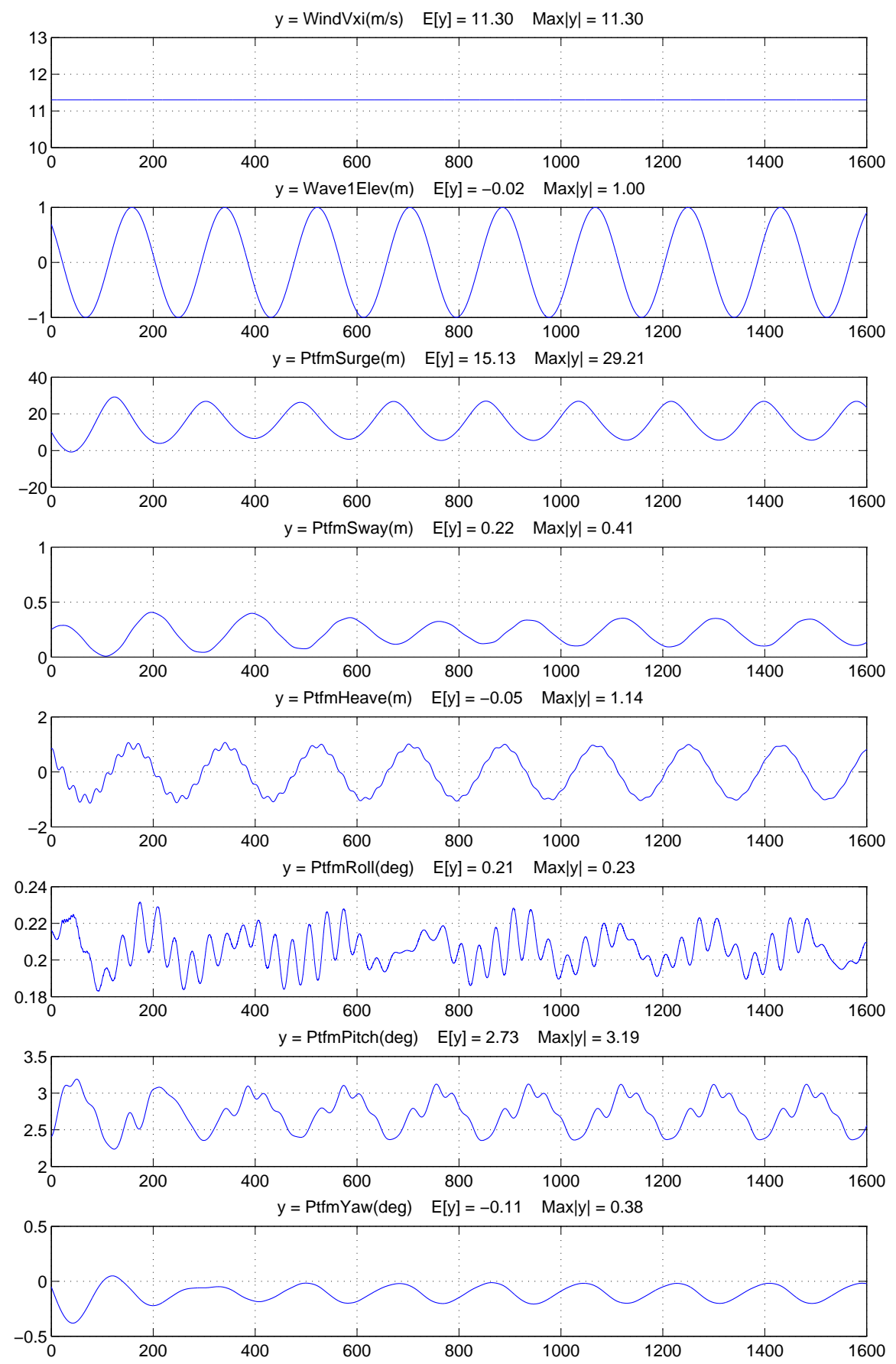

Figure 4.2: Time series of the integrated system for a unit-amplitude wave at surge natural frequency of $0.0057 \mathrm{~Hz}$ (for rated wind velocity, $V_{\text {rated }}=11.3$ $\mathrm{m} / \mathrm{s})$ 


\begin{tabular}{|c|c|c|c|c|c|c|c|}
\hline \multirow{2}{*}{ No } & \multicolumn{2}{|c|}{ Sea State } & TwrBsMyt & PtfmSurge & PtfmHeave & PtfmPitch & TFair[1] \\
\hline & $V$ & $H_{s}, T_{p}$ & $(\mathrm{kN}-\mathrm{m})$ & $(\mathrm{m})$ & $(\mathrm{m})$ & (deg) & $(\mathrm{kN})$ \\
\hline 1 & \multirow{3}{*}{9} & $1.0,7.0$ & $2.63 \mathrm{E}+05$ & 13.5 & -0.03 & 1.95 & 3106 \\
\hline 2 & & $2.5,8.0$ & $3.17 \mathrm{E}+05$ & 13.6 & -0.07 & 2.02 & 3112 \\
\hline 3 & & $4.0,9.5$ & $3.33 \mathrm{E}+05$ & 13.7 & -0.15 & 2.24 & 3120 \\
\hline 4 & \multirow{3}{*}{12} & $1.0,6.0$ & $3.04 \mathrm{E}+05$ & 19.3 & -0.05 & 2.45 & 3833 \\
\hline 5 & & $2.5,7.0$ & $3.58 \mathrm{E}+05$ & 16.0 & -0.07 & 2.35 & 3387 \\
\hline 6 & & $4.0,8.5$ & $4.02 \mathrm{E}+05$ & 15.4 & -0.12 & 2.49 & 3323 \\
\hline 7 & \multirow{3}{*}{16} & $2.0,8.0$ & $2.51 \mathrm{E}+05$ & 11.2 & 0.06 & 1.58 & 2875 \\
\hline 8 & & $3.5,8.5$ & $2.95 \mathrm{E}+05$ & 11.2 & 0.10 & 1.67 & 2878 \\
\hline 9 & & $5.0,10.5$ & $2.79 \mathrm{E}+05$ & 11.5 & 0.32 & 1.99 & 2902 \\
\hline
\end{tabular}

Table 4.2: Maximum values of the steady-state response of the integrated system.

are commonly used in the design of floating structures to study their dynamic characteristics. A variety of methods can be used to establish RAOs for a specific offshore structure. Depending on the design stage and system complexity, either a frequency-domain method is used, which involves calculating added-mass, $A_{i j}$, damping, $B_{i j}$, and excitation forces, $X_{i j}$, and solving the dynamic motion equation 4.1 in the frequency domain or a time-domain method is used, which involves calculating the steady-state force directly, due to a series of regular waves with unit amplitude.

$$
[M+A(\omega)] \ddot{x}+B(\omega) \dot{x}+C x=F(\omega)
$$

The consistency of these two alternative methods for floating offshore wind turbines has been discusses in other studies [27], [23]. Results suggest that maximum values from time-domain analyses of the RAOs generally shift 
towards lower frequencies because of the nonlinear and flexible properties of the floating offshore wind turbine. Coupling of the platform motions and of the flexible tower and blades also explains some of the difference.

To account for the nonlinear characteristics of the integrated system, time-domain computations based on white-noise wave excitation using FAST are carried out in this study. Figure 4.3 shows RAOs for three platform motion DOFs for the SNL turbine floating platform model (with every possible DOF represented) subjected to zero wind speed. For comparison, similar RAOs for the OC4 DeepCwind platform model are shown in Fig. 4.4.

As can be seen from Fig. 4.3, energy in the motions is concentrated on low wave frequencies. The coupling between surge and pitch motions is evident at frequencies around $0.01 \mathrm{~Hz}$. Also, response amplitudes are comparable with those for the OC4 DeepCwind platform motions. The SNL 13.2 MW turbine platform's surge motion maximum RAO value is a little larger, around 20 meters at a frequency of $0.0057 \mathrm{~Hz}$, compared to that for OC4 DeepCwind model, which is around 15 meters at a frequency of $0.0089 \mathrm{~Hz}$. The maximum pitch motion response amplitude for the SNL model is around 1.6 degrees at a frequency of $0.03 \mathrm{~Hz}$, which is smaller than that for the OC4 model which is around 2.2 degrees at a frequency of $0.04 \mathrm{~Hz}$. The somewhat lower frequencies for peak response in the SNL model may be explained by the increased system mass compared to that for the OC4 model. In summary, the behavior of the SNL 13.2 MW turbine platform model is reasonable and in an expected range and comparable to that of the semi-submersible platform used in the 

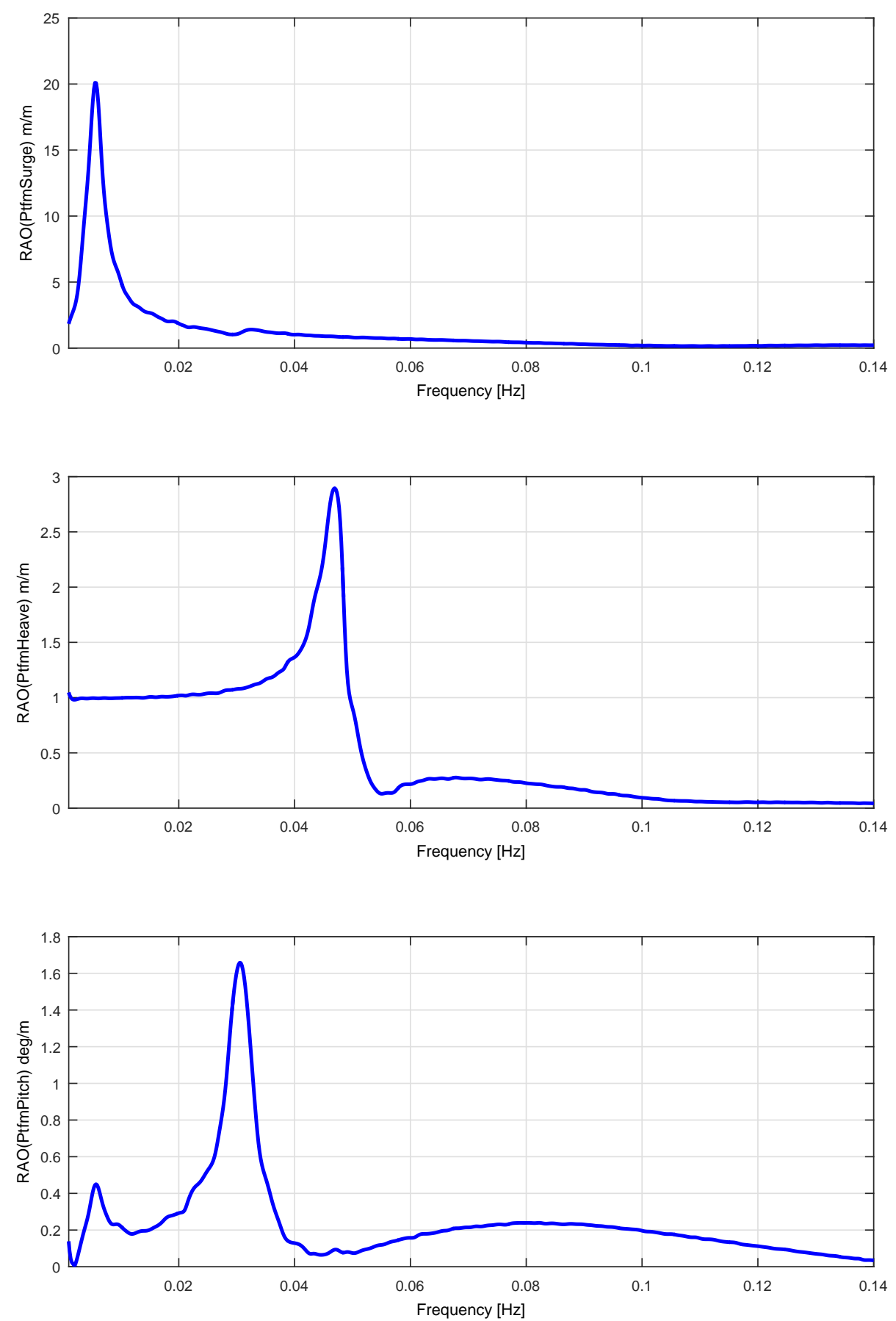

Figure 4.3: SNL 13.2 MW turbine's semi-submersible platform RAOs under zero wind speed 

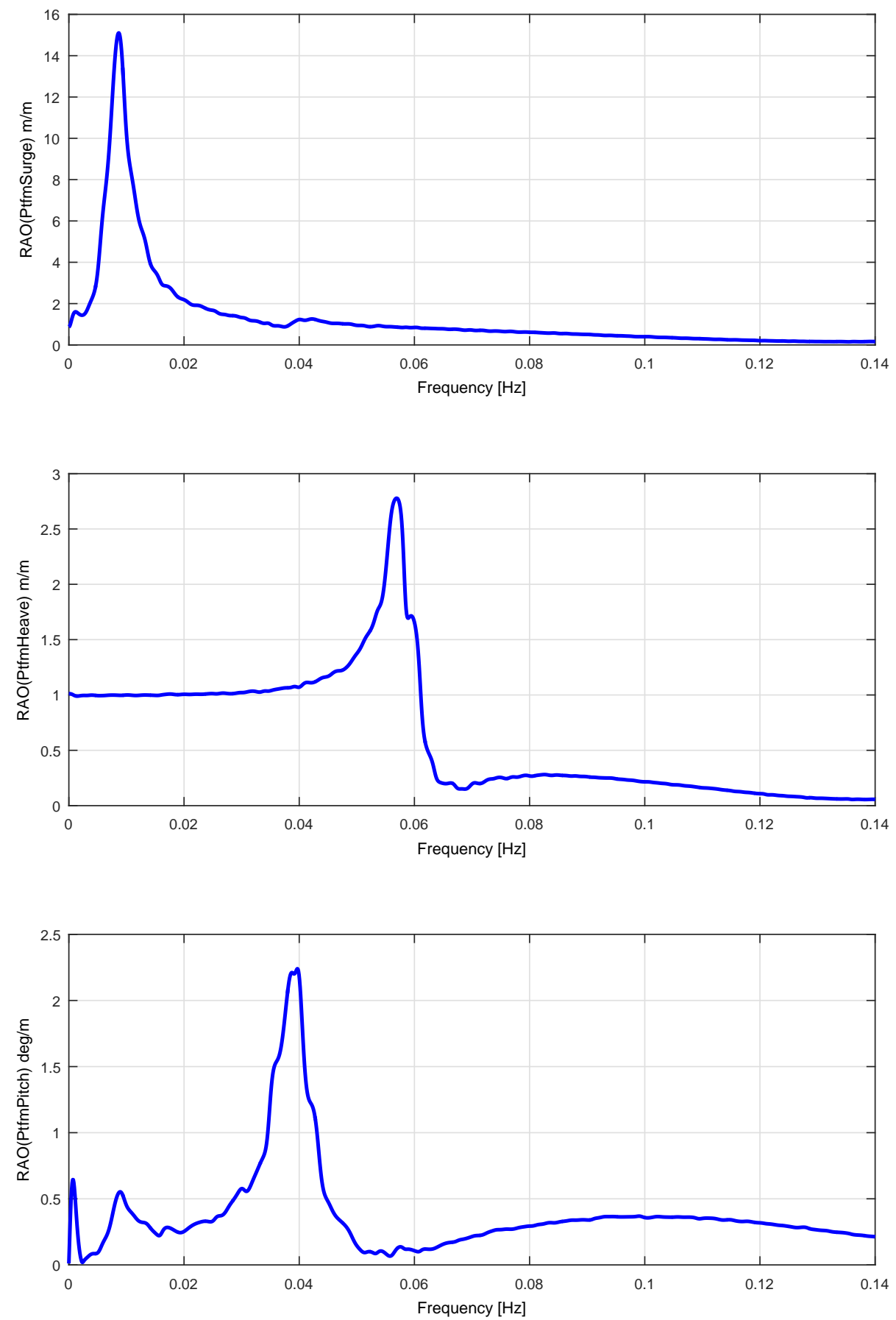

Figure 4.4: OC4 DeepCwind Semi-submersible RAOs under zero wind speed 
OC4 study. Time-domain simulations under sea states associated with rated and cut-out wind speeds are considered next in order to assess the extreme performance of the integrated system.

\subsection{Dynamic Response Analysis under Turbulent Winds and Irregular Waves}

The dynamic response analysis of the integrated system under a turbulent wind field and irregular waves is considered next. The turbulent wind field is generated using a stochastic full-field turbulence simulator, TurbSim [12], developed at NREL. The JONSWAP wave spectrum is used to simulate irregular long-crested waves. MAP is utilized to compute the response of mooring lines. Thus, a wind field over a $260 \mathrm{~m} \times 260 \mathrm{~m}$ vertical plane centered on the rotor is generated in TurbSim using IEC Kaimal spectra using NTM conditions and turbulence category A. A power-law profile on the rotor disk defines the mean wind shear.

At a site of interest, sea states for this model have been identified where the hub-height wind velocity ranges from $11 \mathrm{~m} / \mathrm{s}$ to $18 \mathrm{~m} / \mathrm{s}$ [31], [32]. A total of 10 one-hour long simulations are performed under operating conditions with aligned wind and waves for each sea state. Time series following an initial transient period for two sea states - one with near-rated winds and the other near cut-out - are presented in Figs. 4.5 and 4.6 along with relevant statistics. These two sea states are selected because extreme response levels generally occur around rated winds and/or close to cut-out winds for many wind turbines. 
Blade pitch control influences are evident in the response time series when the hub-height wind speed is larger than the rated wind speed, $V_{r}$, of 11.3 $\mathrm{m} / \mathrm{s}$. This pitch control significantly reduces the fore-aft tower-base bending moment at cut-out compared to at the rated wind speed; this is also true for platform surge motion as these two response quantities are greatly influenced by aerodynamic loads. The platform pitch motion vibrates around an offset value that is induced by the mean wind speed. Note that the pitch motion is always within the desired limit (i.e., less than 10 degrees). Two anchor tension force time series are presented: Anchor 1 is in an upwind position on the platform and Anchor 2 is downwind. The anchor tension response suggests that, during this simulation, while there is no uplift at Anchor 2, tension forces are significant for Anchor 1. Overall, a comparison of the integrated system response between rated and cut-out wind speeds suggests that most response processes have are dominated by winds around the rated wind speed.

The platform pitch is of greatest interest since it was related to one of the primary design criteria for this model and can also have a direct influence on the power efficiency. Table 4.3 summarizes statistics of the platform pitch motion for 50-year return period sea states [31], [32]. For each sea state, 10 one-hour long simulations are performed under operating conditions and for aligned wind and waves. A total of 240 simulations are carried out; response maxima from ten simulations for each sea state are presented - for example, the Max is the maximum value of the 10 platform pitch motion maxima from those ten simulations. 

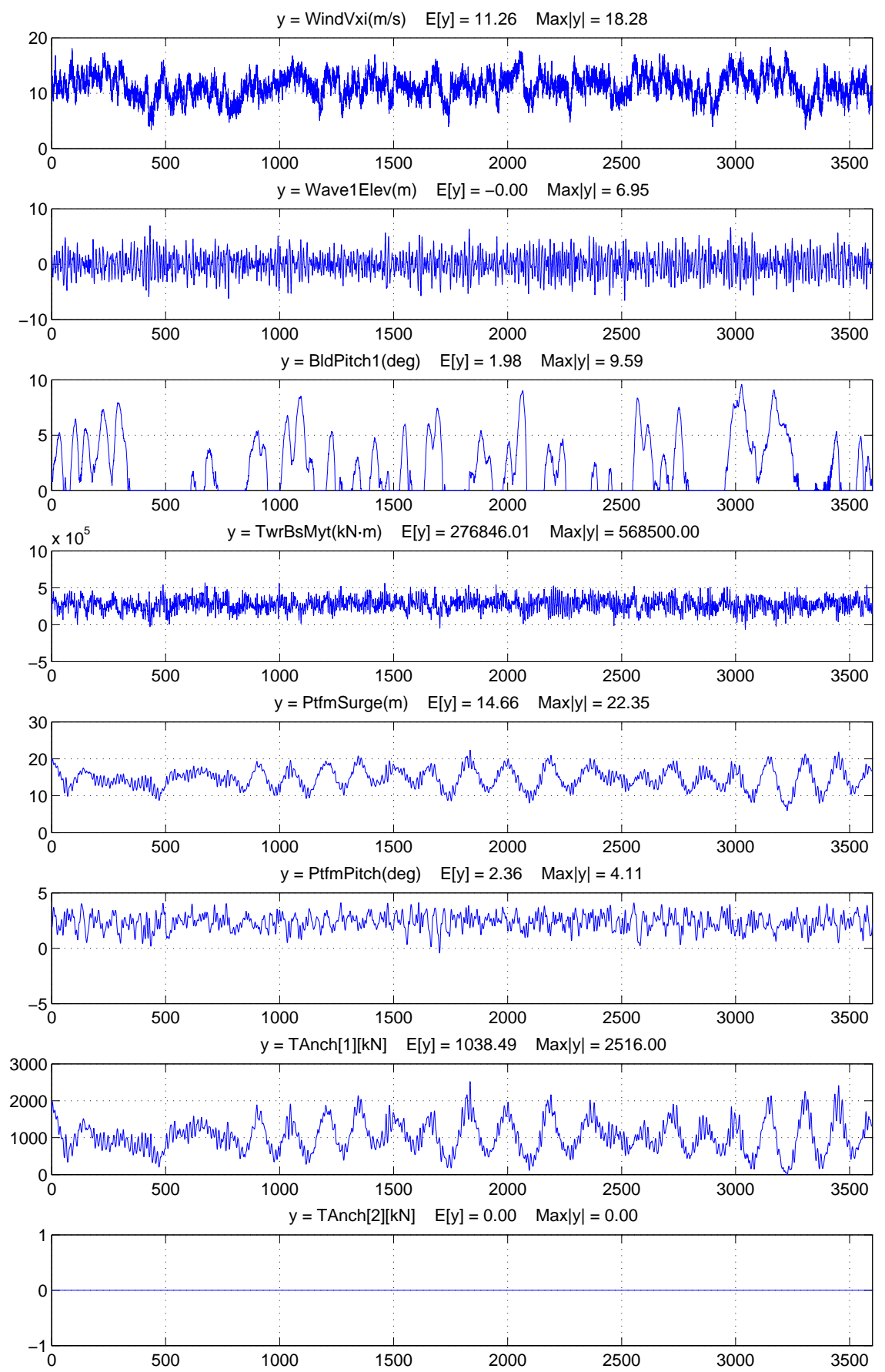

Figure 4.5: One-hour time series of the SNL 13.2 MW turbine-platform integrated system $\left(V_{h u b}=11.3 \mathrm{~m} / \mathrm{s}, H_{s}=7.77 \mathrm{~m}, T_{p}=14.43 \mathrm{~s}\right)$ 

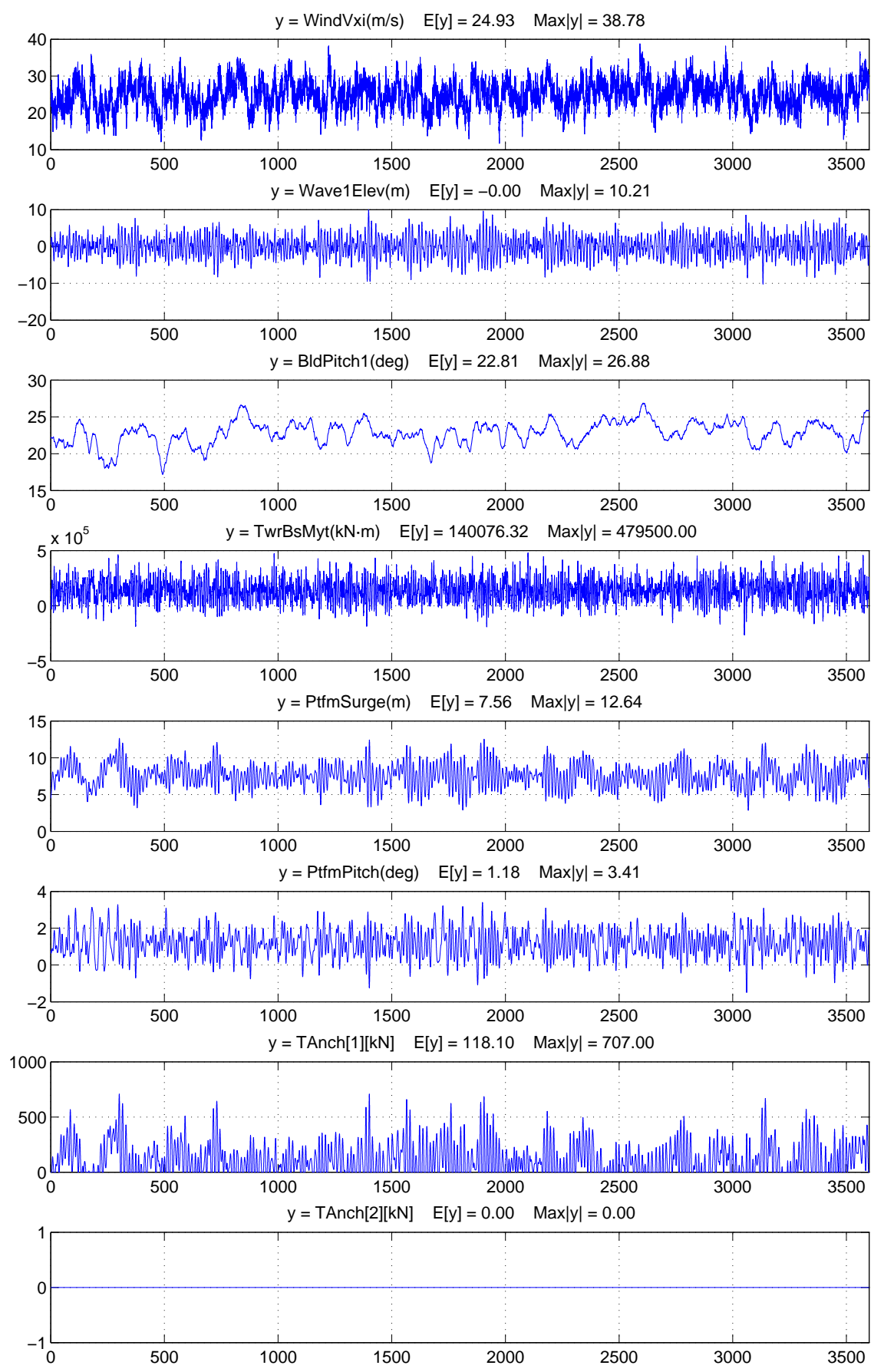

Figure 4.6: One-hour time series of the SNL 13.2 MW turbine-platform integrated system $\left(V_{h u b}=25.0 \mathrm{~m} / \mathrm{s}, H_{s}=11.52 \mathrm{~m}, T_{p}=14.31 \mathrm{~s}\right)$ 


\begin{tabular}{|c|c|c|c|c|c|c|c|c|c|}
\hline $\begin{array}{c}V_{\text {wind }} \\
(\mathrm{m} / \mathrm{s})\end{array}$ & Max & $\sigma$ & Median & $\begin{array}{c}\text { max/ } \\
\text { median }\end{array}$ & $\begin{array}{c}V_{\text {wind }} \\
(\mathrm{m} / \mathrm{s})\end{array}$ & Max & $\sigma$ & Median & $\begin{array}{c}\text { max/ } \\
\text { median }\end{array}$ \\
\hline 3 & 1.41 & 0.07 & 1.30 & 1.09 & 4 & 1.90 & 0.15 & 1.60 & 1.19 \\
\hline 5 & 2.28 & 0.15 & 2.02 & 1.13 & 6 & 2.73 & 0.12 & 2.50 & 1.09 \\
\hline 7 & 3.06 & 0.10 & 2.95 & 1.04 & 8 & 3.58 & 0.13 & 3.38 & 1.06 \\
\hline 9 & 4.11 & 0.19 & 3.77 & 1.09 & 10 & 4.46 & 0.15 & 4.21 & 1.06 \\
\hline 11 & 4.85 & 0.22 & 4.30 & 1.13 & 11.3 & 4.75 & 0.19 & 4.30 & 1.11 \\
\hline 12 & 4.85 & 0.19 & 4.44 & 1.09 & 13 & 4.76 & 0.19 & 4.44 & 1.07 \\
\hline 14 & 4.76 & 0.24 & 4.33 & 1.10 & 15 & 4.94 & 0.34 & 4.42 & 1.12 \\
\hline 16 & 4.99 & 0.29 & 4.37 & 1.14 & 17 & 4.83 & 0.36 & 4.29 & 1.13 \\
\hline 18 & 4.95 & 0.42 & 3.98 & 1.24 & 19 & 4.65 & 0.38 & 3.78 & 1.23 \\
\hline 20 & 4.31 & 0.34 & 3.69 & 1.17 & 21 & 3.97 & 0.24 & 3.55 & 1.12 \\
\hline 22 & 3.94 & 0.25 & 3.51 & 1.12 & 23 & 3.86 & 0.22 & 3.51 & 1.10 \\
\hline 24 & 3.86 & 0.23 & 3.52 & 1.10 & 25 & 3.84 & 0.19 & 3.55 & 1.08 \\
\hline
\end{tabular}

Table 4.3: Statistics of the SNL 13.2 MW turbine's platform pitch motion.

For both regular waves with no wind or steady wind as well as for irregular waves with turbulent wind fields, response levels of the integrated 13.2 MW turbine-platform-mooring system are found to be reasonable and within the design criteria. Overall, the response of the integrated system suggests that this system meets all the typical essential design requirements. From the maximum response levels found in all the simulations, we conclude that this model could survive in fairly severe and even extreme sea states. Additionally, design load cases (DLCs) as defined in IEC 61400-3 need to be performed and analyzed for further validation of the model development presented in this study. 


\section{Chapter 5}

\section{Conclusions}

\subsection{Summary and Conclusions}

Many floating offshore wind turbine models have been proposed and studied to exploit abundant offshore wind energy available. Among these models, one that is often used is the NREL 5-MW offshore wind turbine, whose blades are about 60 meters long [15]. To take advantage of stronger and smooter (less turbulent) winds offshore and to avoid transportation and construction constraints associated with land-based turbines, large-scale wind turbines, such as the 10-MW turbine studied as part of the European Union

UpWind project, are being considered because they offer great economies of scale.

The objective of this study was to develop a semi-submersible floating platform model that will support an innovative 13.2 MW horizontal-axis wind turbine with 100-meter long blades that has been developed at Sandia National Laboratories (SNL) [10]. After an iterative model development procedure and various analyses, the following general conclusions are made:

1. An earlier semi-submersible platform model with a scale factor of 1.8 (on the OC4 model) for the 13.2 MW turbine was over-designed. A 
more economical model with a scale factor of 1.5 for the platform and a mooring line scale factor of 2.0 was found to be adequate for the $13.2 \mathrm{MW}$ wind turbine with SNL100-02 blades in stability and dynamic analyses.

2. A new tower model was designed to support the wind turbine mounted on the semi-submersible platform. The tower height and thickness were chosen to meet design constraints such as an air gap or clearance requirement. A Campbell diagram analysis showed that the tower developed is in the soft-stiff design range and avoids resonance with important rotor rotation and blade-passing frequencies.

3. Platform hydrodynamic properties were calculated using WAMIT, only considering linear hydrodynamic effects. KC numbers for several sea states were computed and it was shown that the application of potential flow theory to this large-volume platform model can be justified. Computed hydrodynamic coefficients for the model developed are consistent with those for the OC4 DeepCwind model

4. The steady-state response of the integrated system showed that it behavior is satisfactory based on the design criteria. Static offsets in pitch and heave motions were in a reasonable range and short-term maximum values were sufficiently low to help validate the model.

5. Response amplitude operators were generated for this integrated model in the time domain to account for nonlinear characteristics based on 
white-noise wave excitation using FAST. Response amplitudes are comparable with those for the OC4 DeepCwind model but the dominant frequencies were somewhat lower, suggesting that this system is more sensitive to low-frequency forces.

6. The performance of the integrated system under a turbulent wind field and irregular waves demonstrated its stability and satisfactory performance. Satisfactory pitch motion statistics including maxima, in the sea states studies, suggest that the model developed is adequate even for use in severe sea states.

\subsection{Suggestions for Future Research}

Even though this model was found acceptable in performance under various design constraints, future work could be undertaken in several research areas to further improve the model.

First, the platform geometry could be further refined since this semisubmersible platform provides more adequate pitch restoring capability compared to that for heave motions. The tower model could be redefined with a more accurate finite element tool. The mooring system could be further studies to yield a more specific mooring pattern based on the specific location and metocean conditions. From the response amplitude operators (RAOs) computed for the platform model, it is noted that various natural frequencies for this platform are lower than those for the OC4 platform. The effect of 
second-order slow-drift forces on semi-submersible floating platforms for offshore wind turbines has been demonstrated [2] and these effects are likely to be more significant for the model developed in this study. Additional loads analysis including evaluation of fatigue and extreme loads should be systematically evaluated and the design load cases in IEC 61400-3 should be evaluated. 


\section{Bibliography}

[1] U.S. Wind Industry First Quarter 2015 Market Report: Executive summary. Technical report, American Wind Energy Association, Washington, DC., 2015.

[2] I. Bayati, J. Jonkman, A. Robertson, and A. Platt. The effects of secondorder hydrodynamics on a semisubmersible floating offshore wind turbine. In Journal of Physics: Conference Series, volume 524, page 012094. IOP Publishing, 2014.

[3] M. Borg, L. Manuel, M. Collu, and J. Liu. Long-term global performance analysis of a vertical-axis wind turbine supported on a semi-submersible floating platform. In 34th International Conference on Ocean, Offshore and Arctic Engineering, ASME, pages V009T09A066-V009T09A066. American Society of Mechanical Engineers, 2015.

[4] B.H. Bulder, M. T. Van Hees, A. Henderson, R.H.M. Huijsmans, J.T.G. Pierik, E.J.B. Snijders, G.H. Wijnants, and M.J. Wolf. Study to feasibility of and boundary conditions for floating offshore wind turbines. ECN, MARIN, Lagerway the Windmaster, TNO, TUD, Technical Report, (2002-CMC):R43, 2002.

[5] National Data Buoy Center. Metocean data for station 46012. http:// 
www.ndbc.noaa.gov/station_page.php?station $\backslash=46012$. Accessed: 2014-8.

[6] International Electrotechnical Commission. IEC 61400-3. Wind Turbines - Part 3, 2009.

[7] O. Faltinsen. Sea loads on ships and offshore structures. Cambridge University Press, 1993.

[8] M. Fowler, D. Bull, and A. Goupee. A comparison of platform options for deep-water floating offshore vertical axis wind turbines: An initial study. Sandia National Laboratories Technical Report, SAND2014-16800, 2014.

[9] D. T. Griffith. The SNL100-02 Blade: Advanced core material design studies for the Sandia 100-meter blade. Sandia National Laboratories Technical Report, SAND2013-10162, 2013.

[10] D. T. Griffith and B. R. Resor. Description of Model Data for SNL13.200-Land: A 13.2 MW land-based turbine model with SNL100-00 blades. Sandia National Laboratories Technical Report, SAND2011-9310P, 2011.

[11] GWEC. Growth of the Wind Power Industry around the World. http: //www.gwec.net/global-figures/graphs/. Accessed: 2015-11-21.

[12] B. J. Jonkman. TurbSim user's guide: version 1.50. National Renewable Energy Laboratory Golden, CO, USA, 2009. 
[13] J. M. Jonkman. Dynamics modeling and loads analysis of an offshore floating wind turbine. 2007.

[14] J. M. Jonkman and M. L. Buhl Jr. FAST User's Guide. Technical Report No. NREL/EL-500-38230, National Renewable Energy Laboratory, Golden, CO, 2005.

[15] J. M. Jonkman, S. Butterfield, W. Musial, and G. Scott. Definition of a 5-MW reference wind turbine for offshore system development. National Renewable Energy Laboratory Golden, CO, 2009.

[16] J. M. Jonkman and D. Matha. A quantitative comparison of the responses of three floating platforms. National Renewable Energy Laboratory Golden, CO, USA, 2010.

[17] Sandia National Laboratories. Offshore Wind RD\&D: Large Offshore Rotor Development. http://energy.sandia.gov/energy/renewable-energy/ wind-power/offshore-wind/offshore-wind-sandia-large-rotor-development/. Accessed: 2015-11-21.

[18] C. H. Lee and J. N. Newman. WAMIT user manual, version 7.0. WAMIT, Inc., Chestnut Hill, MA, 2013.

[19] L. Li, Z. Gao, and T. Moan. Joint environmental data at five European offshore sites for design of combined wind and wave energy devices. In ASME 2013 32nd International Conference on Ocean, Offshore and Arctic 
Engineering, pages V008T09A006-V008T09A006. American Society of Mechanical Engineers, 2013.

[20] S. Lindenberg, B. Smith, and K. ODell. $20 \%$ wind energy by 2030. National renewable energy laboratory (NREL), US department of energy, renewable energy consulting services, energetics incorporated, 2008.

[21] J. F. Manwell, J. G. McGowan, and A. L. Rogers. Wind energy explained: theory, design and application. John Wiley \& Sons, 2010.

[22] M. Masciola, X. Chen, and Q. Yu. Evaluation of the dynamic-responsebased intact stability criterion for floating wind turbines. In ASME 2015 34th International Conference on Ocean, Offshore and Arctic Engineering, pages V009T09A069-V009T09A069. American Society of Mechanical Engineers, 2015.

[23] D. Matha. Model development and loads analysis of an offshore wind turbine on a tension leg platform with a comparison to other floating turbine concepts. Technical report, National Renewable Energy Laboratory (NREL), Golden, CO., 2010.

[24] W. Musial and B. Ram. Large-scale offshore wind power in the united states: Assessment of opportunities and barriers. Technical report, National Renewable Energy Laboratory (NREL), Golden, CO., 2010.

[25] J. N. Newman. Marine hydrodynamics. MIT press, 1977. 
[26] American Bureau of Shipping. Guide for building and classing floating offshore wind turbine installations. 2015.

[27] G.K.V. Ramachandran, A. Robertson, J.M. Jonkman, and M.D. Masciola. Investigation of response amplitude operators for floating offshore wind turbines. 2013.

[28] A. Robertson, J. M. Jonkman, M. Masciola, H. Song, A. Goupee, A. Coulling, and C. Luan. Definition of the semisubmersible floating system for phase II of OC4. Offshore Code Comparison Collaboration Continuation (OC4) for IEA Task, 30, 2012.

[29] H. Sabziyan, H. Ghassemi, F. Azarsina, and S. Kazemi. Effect of mooring lines pattern in a semi-submersible platform at surge and sway movements. Journal of Ocean Research, 2(1):17-22, 2014.

[30] W. Sahasakkul. Development of a model for an offshore wind turbine supported by a moored semi-submersible platform. Master's thesis, University of Texas at Austin, 2014.

[31] E. Thomas. Long-term loads on a large offshore wind turbine supported by a semi-submersible platform. Master's thesis, University of Texas at Austin, 2016.

[32] E. Thomas, J. Liu, A. Goyal, and L. Manuel. Long-term loads on a large offshore wind turbine supported by a semi-submersible platform. The American Institute of Aeronautics and Astronautics, 2016. 
[33] C. C. H. Tracy. Parametric design of floating wind turbines. PhD thesis, Massachusetts Institute of Technology, 2007.

[34] J. van Santen. The use of energy build up to identify the most critical heeling axis direction for stability calculations for floating offshore structures. In Contemporary Ideas on Ship Stability and Capsizing in Waves, pages 193-216. Springer, 2011.

[35] E. N Wayman. Coupled dynamics and economic analysis of floating wind turbine systems. PhD thesis, Massachusetts Institute of Technology, 2006. 


\section{Vita}

Jinsong Liu received the Bachelor of Engineering degree in Naval Architecture and Ocean Engineering from Shanghai Jiao Tong University, China in July 2013. He started his graduate studies in the Department of Civil, Architectural and Environmental Engineering at the University of Texas at Austin in August 2013.

Email Address: jinsongliu@utexas.edu

This thesis was typeset with $\mathrm{HT}_{\mathrm{E}} \mathrm{X}^{\dagger}$ by the author.

\footnotetext{
${ }^{\dagger} \mathrm{HT}_{\mathrm{E}} \mathrm{X}$ is a document preparation system developed by Leslie Lamport as a special version of Donald Knuth's $\mathrm{T}_{\mathrm{E}} \mathrm{X}$ Program.
} 